\title{
Cellular and Network Mechanisms May Generate Sparse Coding of Sequential Object Encounters in Hippocampal-Like Circuits
}

\author{
Anh-Tuan Trinh, ${ }^{1}$ Stephen E. Clarke, ${ }^{3}$ Erik Harvey-Girard, ${ }^{1}$ and ${ }^{\circledR}$ Leonard Maler ${ }^{1,2}$
}

https://doi.org/10.1523/ENEURO.0108-19.2019

${ }^{1}$ Department of Cellular and Molecular Medicine, University of Ottawa, Ottawa, Ontario $\mathrm{K} 1 \mathrm{H} 8 \mathrm{M} 5$, Canada, ${ }^{2} \mathrm{Brain}$ and Mind Institute, Center for Neural Dynamics, University of Ottawa, Ottawa, Ontario K1H 8M5, Canada, and ${ }^{3}$ Department of Bioengineering, Stanford University, Stanford, CA 94305

\begin{abstract}
The localization of distinct landmarks plays a crucial role in encoding new spatial memories. In mammals, this function is performed by hippocampal neurons that sparsely encode an animal's location relative to surrounding objects. Similarly, the dorsolateral pallium (DL) is essential for spatial learning in teleost fish. The DL of weakly electric gymnotiform fish receives both electrosensory and visual input from the preglomerular nucleus (PG), which has been hypothesized to encode the temporal sequence of electrosensory or visual landmark/food encounters. Here, we show that DL neurons in the Apteronotid fish and in the Carassius auratus (goldfish) have a hyperpolarized resting membrane potential (RMP) combined with a high and dynamic spike threshold that increases following each spike. Current-evoked spikes in DL cells are followed by a strong small-conductance calcium-activated potassium channel (SK)-mediated after-hyperpolarizing potential (AHP). Together, these properties prevent high frequency and continuous spiking. The resulting sparseness of discharge and dynamic threshold suggest that DL neurons meet theoretical requirements for generating spatial memory engrams by decoding the landmark/food encounter sequences encoded by PG neurons. Thus, DL neurons in teleost fish may provide a promising, simple system to study the core cell and network mechanisms underlying spatial memory.
\end{abstract}

Key words: hippocampus-like; recurrent network; sparse coding; spike threshold adaptation; time cell; weakly electric fish

\section{Significance Statement}

To our knowledge, this is first study of the intrinsic physiology of teleost pallial (DL) neurons. Their biophysical properties demonstrate that DL neurons are sparse coders with a dynamic spike threshold leading us to suggest that they can transform time-stamped input into spatial location during navigation. The concept of local attractors (bumps) that potentially move "across" local recurrent networks has been prominent in the neuroscience theory literature. We propose that the relatively simple and experimentally accessible DL of teleosts may be the best preparation to examine this idea experimentally and to investigate the properties of local (excitatory) recurrent networks whose cells are endowed with, e.g., slow spike threshold adaptation dynamics.

\section{Introduction}

The mammalian hippocampus is required for the storage and recall of spatial memory that presumably guides

Received March 19, 2019; accepted July 12, 2019; First published July 19, 2019.

The authors declare no competing financial interests. path integration and landmark based navigation (Barry and Burgess, 2014; Hartley et al., 2014). Conventionally, sparse discharge of dentate gyrus (DG) granule cells and 
CA1/CA3 pyramidal cells can encode a rodent's location with respect to visually identified landmarks (Barry and Burgess, 2014; Hartley et al., 2014). An emerging alternate view of hippocampal function emphasizes its role in the encoding of temporal sequences within or across periods of locomotion (Pastalkova et al., 2008; MacDonald et al., 2011; Kraus et al., 2013; Eichenbaum, 2014; Modi et al., 2014; Ranganath and Hsieh, 2016). For example, hippocampal neurons may discharge at specific times after the initiation of running and effectively tile an entire running episode (Kraus et al., 2013). The encoding of time and location appears to be closely connected with the responses of a subset of neurons to time spent and distance traveled (Kraus et al., 2013; Deuker et al., 2016; Eichenbaum, 2017).

Visuospatial memory is also important for teleost fish (Rodríguez et al., 2002), and they can learn to finely discriminate between visual inputs (Schluessel and Bleckmann, 2005; Siebeck et al., 2009; Rischawy and Schuster, 2013; Newport et al., 2016). Unlike mammals, fish do not have an obvious cortex or hippocampus; instead, their dorsal telencephalon (pallium) is divided into non-layered cell groups that have specific connectivity and function (Rodríguez et al., 2002; Northcutt, 2008; Giassi et al., $2012 b, c)$. Visual input to the pallium primarily arrives from the optic tectum and reaches the dorsolateral pallium (DL) through the thalamus-like preglomerular nucleus (PG; Yamamoto and Ito, 2008; Giassi et al., 2012b; Wallach et al., 2018). Lesion studies have shown that DL is essential for visual (landmark) based spatial learning and memory (Rodríguez et al., 2002).

Comparisons of teleost pallium to mammalian dorsal telencephalon has been controversial, and similarity between DL and either hippocampus or cortex have been stressed. Based on its location (Yamamoto et al., 2007; Mueller and Wullimann, 2009), extrinsic connections (Elliott et al., 2017), and molecular markers (Harvey-Girard et al., 2012; Ganz et al., 2014), it has been proposed that $\mathrm{DL}$ is homologous to the hippocampus (in particular to DG; Elliott et al., 2017). However, unlike the major recipients of sensory information in the hippocampal formation (i.e., DG, CA1), DL neurons have strong local recurrent connectivity (Trinh et al., 2016). DL's extrinsic and intrinsic connectivity also suggests a strong resemblance to the mammalian cortex (Yamamoto et al., 2007; Giassi et al., 2012b; Trinh et al., 2016; Elliott et al., 2017). However, DL neurons are morphologically very different from both DG

This work was supported by the Canadian Institutes of Health Research Grant 153143 and by the Natural Sciences and Engineering Research Council Grant 04336 (to L.M.).

Acknowledgements: We thank William Ellis for technical support and Maria Lambadaris for her help with the electrophysiological recordings. We also thank Jean-Claude Béïque, Richard Naud, and Timal Kannangara for their helpful discussions and suggestions.

Correspondence should be addressed to Anh-Tuan Trinh at atrin054@ uottawa.ca.

https://doi.org/10.1523/ENEURO.0108-19.2019

Copyright (C) 2019 Trinh et al.

This is an open-access article distributed under the terms of the Creative Commons Attribution 4.0 International license, which permits unrestricted use, distribution and reproduction in any medium provided that the original work is properly attributed. granule cells and the pyramidal cells of the hippocampus and cortex (Giassi et al., 2012c).

A teleost subgroup, the weakly electric gymnotiform fish, can use their electrosensory system to finely discriminate temporal (Harvey-Girard et al., 2010) and spatial (Graff et al., 2004; Dangelmayer et al., 2016) patterns and use electrosensory-identified landmarks to learn the spatial location of food (Jun et al., 2016). Electrosensory input is first processed in the hindbrain electrosensory lobe (ELL) and, via a midbrain relay, then mapped onto the tectum (Krahe and Maler, 2014). Electrosensory and visual tectal cells then project to PG and their PG target then projects exclusively to DL (Giassi et al., 2012b). Two recent studies have shown that DL cells can process visual and electrosensory inputs. In goldfish, Vinepinsky et al. (2018) have described DL cells responsive to boundaries (visual input) as well as speed and direction of self-motion. In a gymnotiform fish, neurons within a major target of DL (dorsal pallium, DD) have been shown to discharge to the electrosensory signals generated when the fish moves near "landmarks" (Fotowat et al., 2019).

Recently, a subset of electrosensory motion PG neurons have been identified that can encode the time interval between object encounters (Wallach et al., 2018). Wallach et al., hypothesize that the output of these "time stamp" neurons is used to estimate the distance between the objects encountered by the fish, thereby supporting the observed electrosense-dependent spatial learning (Jun et al., 2016). Given the similar anatomic and functional organization of visual and electrosensory motion pathways, we hypothesize that the transformation of electrosensory motion signals to a spatial map are processed in DL. Here, we studied the biophysical properties of DL neurons in vitro to determine if their intrinsic properties are compatible with their putative role in converting temporal input from PG (i.e., time between object encounters) to a spatial map (Wallach et al., 2018).

\section{Materials and Methods}

For the following experiments, we used two closely related Apteronotid fish of either sex (Apteronotus leptorhynchus and Apteronotus albifrons), a suborder of the gymnotiform family, as well as Carassius auratus (goldfish) of either sex. The brains of $A$. leptorhynchus and $A$. albifrons cannot be readily distinguished; these species have been used interchangeably in previous anatomic studies (Carr et al., 1982) and the processing of electrosensory input appears to be nearly identical in these species (Martinez et al., 2016). Goldfish were included in this study for three reasons. First, we found that Apteronotus DL cells were challenging to maintain in slice preparation, whereas goldfish DL cells were more robust, yielding higher success rates on our lengthier protocols involving pharmacological manipulations. Second, we wanted to check how our results generalized to nonelectrosensory teleosts, given the very general mechanisms of sparse neural coding proposed in this article. Last, the critical behavioral experiments on the essential role of $\mathrm{DL}$ in spatial memory were done in goldfish (Rodríguez et al., 2002), setting a precedent in the literature; 


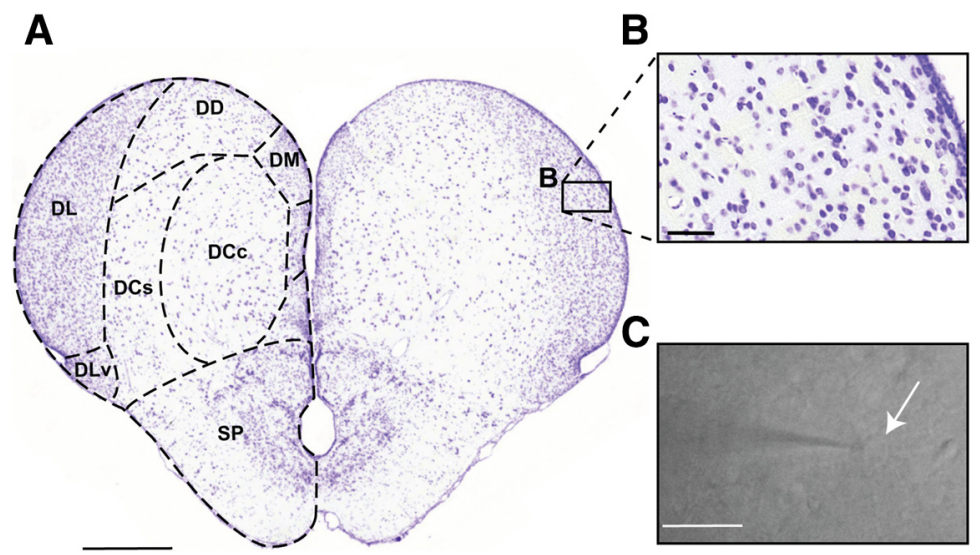

Figure 1. Anatomy of the A. leptorhynchus telencephalon. A, A transverse section through the Apteronotus telencephalon indicating the major subdivisions of pallium and subpallium (SP); this section was obtained from a standard series of cresyl violet-stained sections (Elliott et al., 2017). Midbrain sensory inputs entering the pallium from PG terminates in the DL. These inputs are processed within the DL recurrent network (Trinh et al., 2016). DL projects to the core dorsocentral pallium (DCc) which, in turn, projects to midbrain sensory regions. DL, ventral subdivision (DLv) is located ventral to DL and distinguished by its olfactory bulb input. The dorsal-dorsal pallium (DD) has reciprocal connections with DL (Elliott et al., 2017). Scale bar: $500 \mu \mathrm{m}$. $\boldsymbol{B}$, A higher magnification of the cells in DL illustrates an apparent random distribution and its highly organized intrinsic laminar and columnar circuitry is not evident (Trinh et al., 2016). The neurons in DL have homogenous morphology and are roughly $10 \mu \mathrm{m}$ in diameter (Giassi et al., 2012c). Scale bar: $50 \mu \mathrm{m}$. C, An infrared image of a DL neuron undergoing a whole-cell patch recording. The shadow to the left illustrates the patch pipette, while the white arrow highlights the patched cell. Scale bar: $20 \mu \mathrm{m}$. DCs, dorsocentral pallium, shell; DM, dorsomedial pallium.

further, the first in vivo $\mathrm{DL}$ recordings have also been conducted in goldfish (Vinepinsky et al., 2018). As demonstrated in the results, our conclusions apply equally well to each of these species and are therefore directly relevant to spatial learning across a broad range of teleost fish.

Before use, the Apteronotus fish were kept in heated aquariums at $28^{\circ} \mathrm{C}$, while goldfish were kept in aquariums at $22^{\circ} \mathrm{C}$ (room temperature). All procedures were approved by the University of Ottawa Animal Care Committee and follow the guidelines issued by the Society for Neuroscience.

\section{Slice preparation}

Before the dissection, adult male and female fishes were anesthetized in oxygenated water containing $0.2 \%$ 3-aminobenzoic ethyl ester (tricaine methanesulfonate, Aqua Life, Syndel Laboratories). As the skull was being removed, ice cold oxygenated $\left(95 \% \mathrm{O}_{2}, 5 \% \mathrm{CO}_{2}\right)$ artificial CSF (ACSF; $130 \mathrm{mM} \mathrm{NaCl}, 24 \mathrm{mM} \mathrm{NaHCO}, 10 \mathrm{mM}$ glucose, $2.5 \mathrm{mM} \mathrm{KCl}, 1.75 \mathrm{mM} \mathrm{KH}_{2} \mathrm{HPO}_{4}, 1.5 \mathrm{mM} \mathrm{CaCl}_{2}$, $1.5 \mathrm{mM} \mathrm{MgSO}_{4}$, and $295 \mathrm{mOsm}, \mathrm{pH}$ 7.4), containing 1 $\mathrm{mM}$ of kynurenic acid (Millipore Sigma), was dripped onto the fish's brain. The brain was then carefully removed and submerged in a Petri dish containing ice-cold ACSF with kynurenic acid. Once the brain was removed, it was placed in an ice-cold cubic mold, to which oxygenated ACSF mixed with $2.5 \%$ low-melting agarose (Millipore Sigma) was added. After the agarose has solidified, an initial cut was performed to separate the telencephalon from the rest of the brain. Subsequently, 300- $\mu \mathrm{m}$-thick transverse brain slices of the telencephalon were obtained using a vibratome. For goldfish dissections, a slightly different cutting ACSF was used: $108 \mathrm{mM} \mathrm{NaCl}, 24$ $\mathrm{mM} \mathrm{NaHCO}, 10 \mathrm{mM}$ glucose, $2.5 \mathrm{mM} \mathrm{KCl}, 1.25 \mathrm{mM}$
$\mathrm{KH}_{2} \mathrm{HPO}_{4}, 1.5 \mathrm{mM} \mathrm{CaCl}_{2}, 1.5 \mathrm{mM} \mathrm{MgSO}_{4}$, and $2 \mathrm{mM}$ HEPES, 260 mOsm (adapted from Palmer, 2006). Furthermore, the thick optic nerves underneath the brain had to be severed with micro scissors before the brain was removed and placed in a Petri dish containing ice-cold ACSF. The rest of the dissection was done in the same manner as in Apteronotus (see Trinh et al., 2016). Brain slices containing the dorsolateral telencephalon (DL) were then transferred into a continuously oxygenated slice incubation chamber containing ACSF where they were left to rest for 30-60 min.

\section{In vitro recordings}

After the incubation period, brain slices containing DL were transferred to the recording chamber where oxygenated ACSF was constantly perfused at a flow rate of 3 $\mathrm{ml} / \mathrm{min}$. Recordings were performed at room temperature $\left(23-24^{\circ} \mathrm{C}\right)$. We used fire-polished borosilicate glass micropipettes (Sutter Instruments) with resistances ranging between 8 and $14 \mathrm{M} \Omega$. The intracellular solution contained the following: $130 \mathrm{mM} \mathrm{K}$-gluconate, $10 \mathrm{mM} \mathrm{KCl}, 10$ mM HEPES, $4 \mathrm{mM} \mathrm{NaCl}, 4 \mathrm{mM}$ Mg-ATP, $10 \mathrm{mM}$ phosphocreatine, and $0.3 \mathrm{mM} \mathrm{Na}-\mathrm{GTP}$, with an osmolality of $295 \mathrm{mOsm}$, and a $\mathrm{pH}$ of 7.2 for weakly electric fish recordings. A silver wire plated with silver chloride was used as a ground. For goldfish experiments, recordings were done in the goldfish ACSF as described above and a slightly different intracellular solutions was used: 110 $\mathrm{mM}$ K-gluconate, $10 \mathrm{mM} \mathrm{KCl}, 18 \mathrm{mM}$ HEPES, $4 \mathrm{mM}$ Mg-ATP, $10 \mathrm{mM}$ phosphocreatine, and $0.3 \mathrm{mM}$ Na-GTP, $265 \mathrm{mOsm}, \mathrm{pH}$ 7.2. To visualize the neurons, slices were imaged under differential interference contrast (DIC) optics using a CMOS infrared camera (Scientifica) directly connected to the rig computer (Fig. 1). The recording signals were amplified using a Multiclamp 700B (Molecu- 
lar Devices), while the signal was filtered at $3 \mathrm{kHz}$ and digitized using a Digidata 1550 (Molecular Devices). The whole-cell recording data were acquired using the PClamp 10.6 software (Molecular Devices, RRID: SCR_011323). All recordings were performed in currentclamp mode. Only cells that required a minimal holding current less than $-50 \mathrm{pA}$ were included in the study, allowing to stabilize the cell near the average resting membrane potential (RMP; $\sim 75 \mathrm{mV}$; Fig. 2E). The maximal recording time after the dissection was $4-5 \mathrm{~h}$. Once the whole-cell configuration was obtained, the RMP was recorded for $10 \mathrm{~s}$, and the cells were injected with current steps, which typically range from 500 to $1000 \mathrm{~ms}$ and from -60 to $+60 \mathrm{pA}$, except where otherwise noted. For our ramp current protocol, we injected two different ramp currents at different inter-stimulus time intervals ranging from 50 to $1000 \mathrm{~ms}$. Although both ramp stimuli have the same slope, the first ramp current was always two-fold stronger than the second ramp since the first ramp current had to evoke multiple action potentials while the second one only had to evoke one action potential. As such, the magnitude of the second current injection had to be adjusted for each cell since the rheobase for each cell is different and the magnitude of the first ramp was then adjusted according to the second ramp. Healthy cells were usually held for $30-60 \mathrm{~min}$.

\section{Pharmacology}

A subset of DL cells exhibited membrane "noise." We bath applied the non-selective antagonist, kynurenic acid (10 mM; Millipore Sigma), to block ionotropic glutamatergic transmission to determine if this noise was due to synaptic input to DL cells.

To test for the presence of fast and persistent sodium channels in DL neurons (Berman et al. 2001), we first patched the cell and injected a standard 500-ms current step before applying $20 \mu \mathrm{M}$ tetrodotoxin (TTX; Abcam) locally near the recording site by pressure injection. To further investigate the presence of a persistent sodium channel, we also applied $5 \mathrm{mM}$ lidocaine $\mathrm{N}$-ethyl bromide (QX-314; Millipore Sigma) via the intracellular recording solution to block sodium (Salazar et al., 1996) and other channels (e.g., certain $\mathrm{K}^{+}$channels and $\mathrm{Ca}^{2+}$ channels, see Results; Alreja and Aghajanian, 1994; Perkins and Wong, 1995; Talbot and Sayer, 1996).

Calcium-activated potassium channels SK1/2 are both expressed in DL (Ellis et al., 2008). We used our standard current step protocol to evoke spikes in patched DL cells and bath applied an SK channel blocker $30 \mu \mathrm{M}$ 6,12,19,20,25,26-hexahydro-5,27:13,18:21,24-trietheno11,7-metheno- $7 \mathrm{H}$-dibenzo $[b, n][1,5,12,16]$ tetraazacyclotricosine-5,13-diium dibromide (UCL; Tocris, Bio-Techne). We also locally applied $1 \mathrm{mM}$ 1-ethyl-2-benzimidazolinone (EBIO; Abcam), a SK channel agonist near the brain slice by pressure injection. Finally, we patched neurons using a slightly altered internal solution that contained $10 \mathrm{mM}$ BAPTA (Millipore Sigma) to chelate intracellular calcium. The osmolarity of this intracellular solution was readjusted to 295 mOsm.

\section{RT-PCR}

G-protein-coupled inwardly-rectifying potassium channels (GIRK) 1-4 mRNA sequences were identified from $A$. leptorhynchus brain transcriptome data (Salisbury et al., 2015). Two degenerate PCR primers were designed to bind all GIRK isoform sequences (forward: CTGGTGGACCTSAAGTGGMG; reverse: TTCTTGGGCTGNGNAGATCTT). Five $A$. leptorhynchus fish were anesthetized with tricaine methanesulfonate (Aqua Life, Syndel Laboratories) and then sacrificed by cervical dislocation while being fed oxygenated water containing the anesthetic. Different regions of the brain (DL, tectum/torus, subpallium, cerebellum, ELL, hindbrain) were dissected in icecold ACSF, collected and preserved on dry ice. All tissues were weighed, and homogenized in Trizol to purify total RNA (Millipore Sigma). First-strand cDNAs were then generated by using the RevertAid $\mathrm{H}$ Minus First Strand cDNA Synthesis kit (Fermentas). Degenerate PCR was performed using the DreamTaq, according to the manufacturer recommendations (Thermo Fisher Scientific), with the primers mentioned above. On an agarose gel, the amplicon expected bands were $344 \mathrm{bp}$.

\section{Data analysis}

All the recording data were first visualized in Clampfit (Molecular Devices) before being transferred into MATLAB (MathWorks, RRID: SCR_001622) for subsequent analysis with custom scripts. To reduce the likelihood of analyzing unhealthy cell responses, only cells which produced spikes that cross a data-driven threshold of $-5 \mathrm{mV}$ were included in the analysis. Cells that showed significant membrane noise, i.e., a variance $>0.5 \mathrm{mV}^{2}$, were used to construct Figures 2 and 3 but were excluded from any additional analysis. For the analysis of the RMP (Fig. 2 ), only cells that did not require a holding current to stabilize were included in this analysis. For the analysis of the average RMP (and variance) in Figure 3, a total of 2 min of recording (binned into 10-s sweeps) were analyzed for each cell before and after the addition of the synaptic blocker (for a total of 4 min per cell). If the recording trace contained any spontaneous action potentials, the action potentials were replaced with the membrane potential recorded in the prior $100 \mathrm{~ms}$. The membrane time constant was measured by fitting an exponential function to the neuron's recovery to equilibrium following injection of a negative step current. The spike amplitude was measured by two methods: first, as the difference between the spike height and the spike threshold and, second, from the difference between the spike height and the RMP. To estimate the spike threshold, we used the method of Azouz and Gray (2000) which defined the spike threshold as the voltage corresponding to an empirically defined fraction (0.033) of the peak of the first derivative. This first derivative method was later shown to be slightly better than the second derivative method (Sekerli et al., 2004) previously used for hindbrain electrosensory neurons (Chacron et al., 2007). The threshold for the broad $\mathrm{Ca}^{2+}$ spikes were determined visually in Clampfit since the rate of change of the $\mathrm{Ca}^{2+}$ spike was too slow to be visualize 
A

RMP $=-74 \mathrm{mV}$

RMP $=-77 \mathrm{mV}$

$R M P=-80 m V$

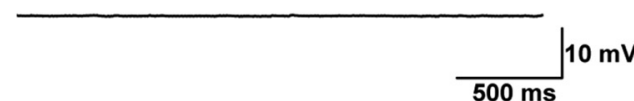

C

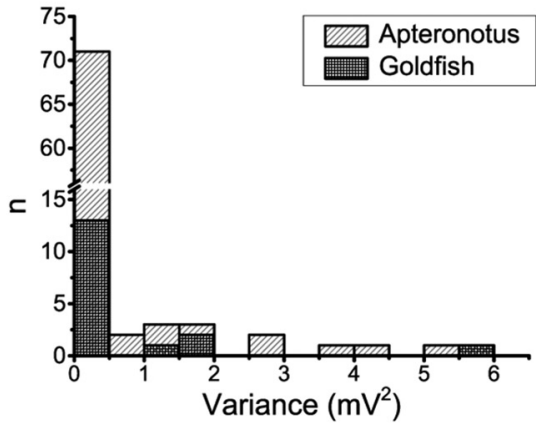

E
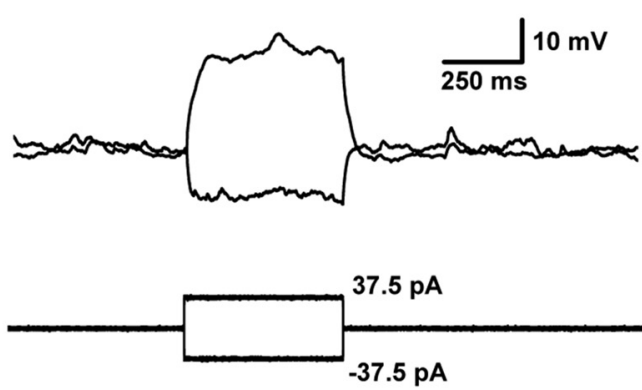

B

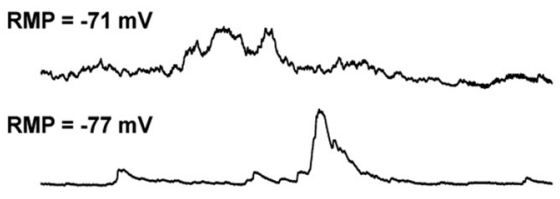

$\mathrm{RMP}=-81 \mathrm{mV}$

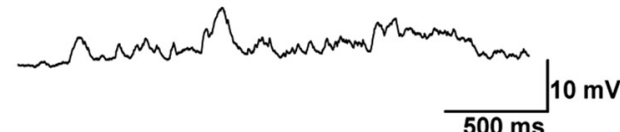

D

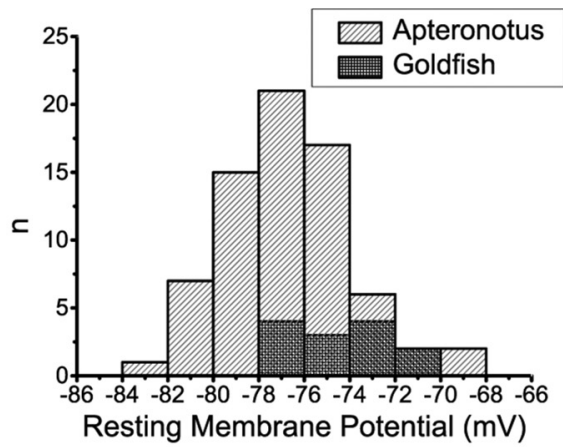

F

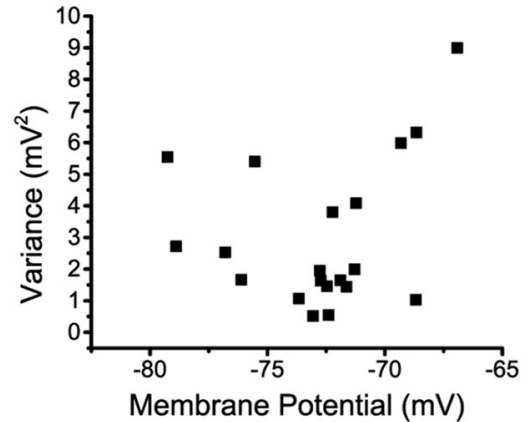

Figure 2. RMP of DL neurons. A, Three example RMP traces taken from three different quiet neurons illustrate the membrane potential at which these cells would normally stabilize at naturally (i.e., no holding current was applied). The RMP at the start of the recording is shown above each trace. $\boldsymbol{B}$, Three example RMP traces taken from three different noisy neurons in which no holding current was applied. In contrast to the quiet cells, these cells exhibited strong membrane fluctuations even when they had stabilized at a hyperpolarized potential. C, A histogram of the RMP variance for Apteronotus (gray) and goldfish (black) DL neurons showing that most neurons were of the quiet type where $n$ is the number of individual 10-s recording traces that were recorded from all cells (Apteronotus, $N=29$ cells; goldfish, $N=7$ cells; total $n=85$ recordings). $\boldsymbol{D}$, A histogram of the natural RMPs in both the Apteronotus and in the goldfish illustrating that the average RMP of DL neurons is around $-77 \mathrm{mV}$ in Apteronotus and around $-73 \mathrm{mV}$ in goldfish (Apteronotus, $N=35$ cells; goldfish, $N=11$ cells; total $n=71$ recordings). $E$, A noisy DL neuron's response to the injection of $\pm 37.5-p A$ current steps in Apteronotus, illustrating that the membrane fluctuations are invariant to the membrane potential of the cell. $\boldsymbol{F}$, A scatter plot of the variance and membrane potential, including all recordings (black dots) that had a variance value above $0.5 \mathrm{mV}^{2}$ (Apteronotus, $N=6$ cells; goldfish; $N=4$ cells; total $n=20$ recordings).

with either the first or second derivative of the membrane potential. The spike width was calculated by measuring the half-width at half-maximum. The voltage, as a function of injected current (I-V curves), was obtained in Clampfit using sub-threshold traces and averaged to reduce the variability across cells caused by the holding current. The input resistance was obtained by calculating the average slope of the I-V curve across all cells. The afterhyperpolarizing potential (AHP) amplitude was measured as the difference between the spike threshold and the minimum value of the AHPs. If the recording trace contained a burst or spike doublet, then the AHP would be measured on the following spike, since a doublet would typically induce an especially large AHP. The cell's average firing rate was calculated as the number of spikes divided by the duration of the stimulus. The $\delta$ spike height was calculated as the difference in spike height between the $n$th spike and the first spike of an evoked spike train. The interspike interval (ISI) was measured as the time between the first two spikes of the spike train induced by 
A

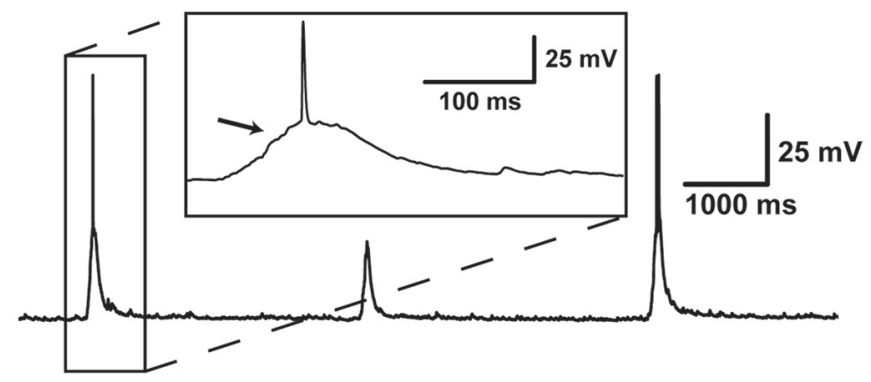

B

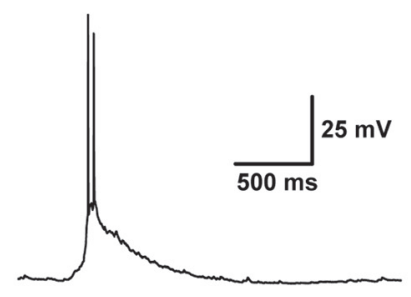

C

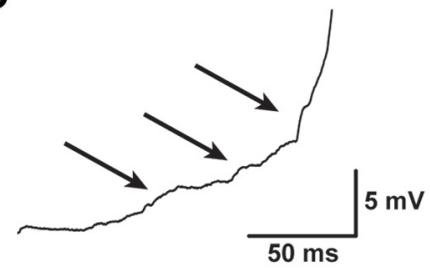

D

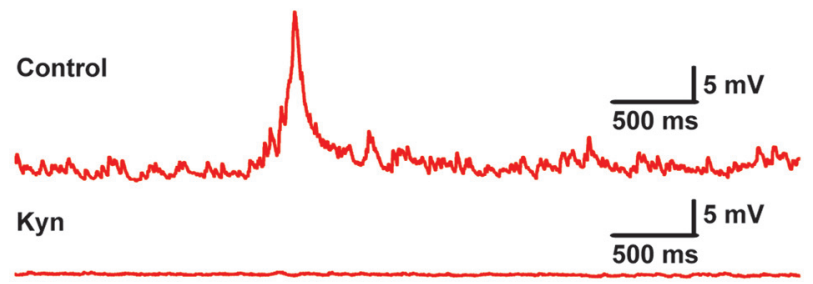

E

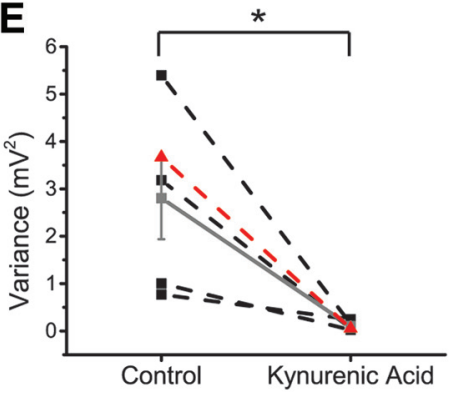

$\mathbf{F}$

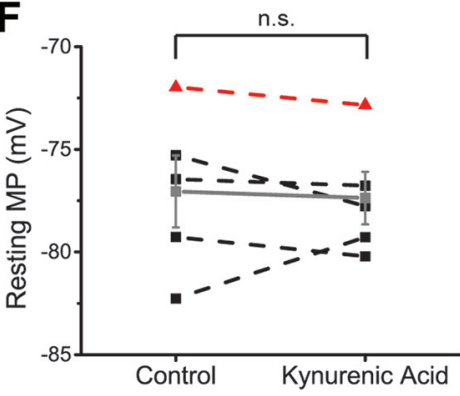

Figure 3. Noisy cells. A, Example recording trace from a noisy cell displaying spontaneous membrane potential fluctuations. These fluctuations often vary in size but are usually in the range of several millivolts and can trigger action potentials (spikes), as highlighted by the box showing a magnified version of the first fluctuation. The arrow within the magnified box highlights an example of the small fluctuations that precede spiking. $\boldsymbol{B}$, Example trace illustrating a spontaneous membrane fluctuation that lasted $865.5 \mathrm{~ms}$ and produced a short burst of 2 action potentials. $\boldsymbol{C}$, A higher magnification of the rise phase of the spontaneous fluctuation shown in panel $\boldsymbol{B}$. The arrows denote small membrane potential fluctuations that appear to summate, giving rise to a sustained depolarization and spiking. $\boldsymbol{D}$, The top trace illustrates an example recording of a noisy cell before the addition of a synaptic blocker. The bottom trace illustrates a recording of the same cell after the addition of $10 \mathrm{mM}$ kynurenic acid. $\boldsymbol{E}$, The average variance of the RMP before and after the bath application of $10 \mathrm{mM}$ kynurenic acid (Apteronotus; $N=3$ cells, goldfish; $N=2$ cells). Each black square represents a cell from either fish and the gray square represents the mean variance. The red triangles depict the average variance of the cell shown in $\boldsymbol{D}$. Of particular note, the wide range of variances all decreased to a similar value after the application of the synaptic blocker. $\boldsymbol{F}$, Same as in $\boldsymbol{E}$ except this graph depicts the RMP instead (Apteronotus; $N=3$ cells, goldfish; $N=2$ cells). Unlike the variance, the RMP was unaffected by the bath application of the synaptic blocker. $* p<0.05$. n.s, not significant.

a current step injection, while the $\delta$ time was calculated as the difference between the time of the first AHP and the time of the $n$th AHP. The $\delta$ AHP was obtained by subtracting the first spike's AHP amplitude from the second spike's AHP amplitude. The $\delta$ threshold was obtained in a similar fashion. All error bars were determined using the standard error of the mean. Wherever applicable, the statistical significance was determined using either oneway ANOVA, two-way ANOVA, one sample $t$ test, two- sample $t$ test or the paired $t$ test, where $p<0.05$ is considered significant.

\section{Inactivating exponential integrate and fire model (iEIF)}

To illustrate the putative role of slow sodium channel inactivation on the observed and variable spike threshold in DL cells, we sought a minimal neuron model that incorporates an abstraction of sodium channel dynamics. The 
inactivating exponential integrate and fire neuron (Eq. 1; Platkiewicz and Brette, 2011) provides a distilled representation of sodium channel activation via an exponential amplification of the membrane voltage $(V)$, which is attenuated by fast and slow inactivation variables $\left(h_{f}\right.$ and $\left.h_{s}\right)$. These sodium channel inactivation terms further affect the dynamic threshold for spike generation, $\theta$, whose initial value $V_{T}$ reflects no inactivation at the RMP (Eqs. 2, $3 ; h_{f}$ $=h_{s}=1$; Platkiewicz and Brette, 2010). Although the exponential approximation does not realistically capture the full action potential wave form, which spans a large voltage range, it is valid for voltages near spike initiation. Importantly, this approximation permits the differential equation for the variable spike threshold, $\theta$, to be simply expressed by sodium channel properties described in Equations 2, 3 (Platkiewicz and Brette, 2010, 2011).

$$
\begin{gathered}
C \frac{d V}{d t}=g_{L} h_{f} h_{s} e \frac{V-V_{T}}{k_{a}}+g_{L}\left(E_{L}-V\right)+I \text { for } V<\theta, \\
\theta=V_{T}-k_{a} \log \left(h_{f} h_{s}\right), \\
V_{T}=V_{a}-k_{a} \log \left(\frac{g_{N a}}{g_{L}} \frac{E_{N a}-V_{a}}{k_{a}}\right) .
\end{gathered}
$$

As in the work of Platkiewicz and Brette (2011), the membrane time constant, $\tau=C / g_{L}=5 \mathrm{~ms}$, was introduced for our simulations. Given that the specific membrane capacitance is $\sim 0.9 \mu \mathrm{F} / \mathrm{cm}^{2}$ for practically all neuron types (Gentet et al., 2000), the leak conductance is constrained to be $g_{L}=0.18 \mathrm{mS} / \mathrm{cm}^{2}$ and the input current, $I=3.8 \mathrm{nA}$, is scaled by the associated membrane resistance $(5.56 \mathrm{M} \Omega)$. The leak current reversal potential was set to $E_{L}=-55$ (Platkiewicz and Brette, 2011). When the membrane voltage reaches $\theta$ at time $t$, a spike is generated and $V\left(t^{+}\right)$is reset to the RMP, $V_{r}=-70 \mathrm{mV}$. The average threshold for the first spike in $\mathrm{DL}$ neurons was $-42.96 \pm 0.5 \mathrm{mV}(\mathrm{N}=42$ spikes). To obtain an approximate match between $V_{T}$ and this value, we kept the sodium activation slope, $k_{a}=4 \mathrm{mV}$, and reversal potential, $V_{a}=-38.6 \mathrm{mV}$, at the empirically justified values used by Platkiewicz and Brette (2011). We then set the sodium conductance to $g_{\mathrm{Na}}=0.036 \mathrm{mS} / \mathrm{cm}^{2}$ to achieve a value of $g_{\mathrm{Na}} / g_{L}=0.2$, near the range of Platkiewicz and Brette (2011). We assume this slightly lower value in our model is a reflection of low sodium channel density. Consistent with this assumption, DL neuron axons are very thin and possibly unmyelinated (Giassi et al., 2012c) suggesting that they have a low sodium channel density, which may partly explains the high DL neuron threshold. The sodium channel reversal potential was kept at a standard $E_{\mathrm{Na}}=$ $50 \mathrm{mV}$. When substituted into Equation 3, the above parameter set yielded an initial threshold of $V_{T}=-44.6$ $\mathrm{mV}$ (see below in the Dynamic AHP and spike threshold section) and gave particularly close agreement with the Apteronotus data $(-45.3 \pm 0.2 \mathrm{mV}$; Fig. $4 E)$.

Drawing on the Hodgkin-Huxley formalism, the inactivation variables, $h_{f}$ and $h_{s}$, evolve according to Equations
4,5 , where $h_{\infty}$ is a Boltzmann equation with inactivation parameters $V_{i}=-63 \mathrm{mV}$ and $k_{i}=6 \mathrm{mV}$ [6]:

$$
\begin{gathered}
\tau_{f} \frac{d h_{f}}{d t}=h_{\infty}(V)-h_{f}, \\
\tau_{f} \frac{d h_{s}}{d t}=h_{\infty}(V)-h_{s}, \\
h_{\infty}(V)=\left(1+e^{\frac{V-V_{i}}{k_{i}}}\right)^{-1} .
\end{gathered}
$$

The parameters $\tau_{f}$ (fast inactivation timescale) and $\tau_{s}$ (slow inactivation timescale) are of particular interest to the model and to our results. To determine $\tau_{f}$, the average time between a short burst of two DL spikes (doublet) was measured at the beginning of the recorded voltage trace, yielding $15.38 \pm 0.6 \mathrm{~ms}\left(N=144\right.$ doublets). Selecting $\tau_{f}=$ $15 \mathrm{~ms}$, we note that the model generates spikes at a frequency of $64.7 \pm 7.8 \mathrm{~Hz}$, consistent with the data mean. We assumed that a slow timescale of inactivation would lead to an increase of spike threshold with a correspondingly long timescale for recovery (see Discussion). To select $\tau_{s}$, we therefore noted that the threshold for DL cell spiking remains significantly increased for at least 300 ms when stimulated; therefore, $\tau_{s}$ is likely on the order of $10^{2} \mathrm{~ms}$. A more direct estimate gave a mean decay time constant $\left(\tau_{\text {exp }}\right)$ of $\sim 640 \mathrm{~ms}$ for the slow recovery (see ramp protocol results below). Therefore, we selected $\tau_{s}=$ $500 \mathrm{~ms}$, which is a conservative value, given slow inactivation is typically $>1 \mathrm{~s}$ and longer timescales would only further strengthen our hypotheses (Itskov et al., 2011).

Note that we omitted $\mathrm{Ca}^{2+}$ currents and the resulting SK channel mediated AHP since its duration is less than the typical ISI of DL neurons. When simulating the model, subthreshold Gaussian noise, $N(0,1)$, was added to Equation 1 and scaled by a factor $\sigma=0.5$. The stochastic forward Euler method was used as the numerical solver.

\section{Code accessibility}

The MATLAB code used in this paper is available as Extended Data 1 and at the University of Ottawa's Institutional repository with the corresponding doi number: 10.20381/ruor39306. A Windows 10 computer was used to simulate the results from the iEIF model.

All panel figures were initially compiled in OriginPro 9.0 (OriginLabs, RRID: SCR_015636) and the final figures were assembled in Adobe Illustrator CS6 (Adobe Systems, RRID: SCR_010279).

\section{Results}

We performed whole-cell patch recordings from Apteronotus DL neurons in acute slices from the rostral- to mid-telencephalon (Fig. 1A). Cells within DL, imaged under infrared illumination with DIC optics, had a shape and size consistent with those identified in Nissl-stained sections (Fig. 1B,C). Although we cannot differentiate between excitatory and inhibitory cells, we assume that the neurons whose biophysical properties we characterize are almost certainly those of excitatory (glutamatergic) DL neurons since they vastly predominate over the rare in- 
hibitory (GABAergic) cells (Giassi et al., 2012c). We also recorded neurons from the dorsal portion of $C$. auratus (goldfish) DL, while avoiding the ventral DL as it receives olfactory bulb input (Northcutt, 2006). The physiology of neurons recorded in the goldfish DL was not distinguishable from those of Apteronotus (see below).

\section{Noisy versus quiet cells}

After attaining the whole-cell patch configuration, we first examined the RMP (no holding current), and observed two distinct electrophysiological profiles. The majority of the DL cells (29/35 cells in Apteronotus and 7/11 cells in goldfish) were quiet, that is, they had minimal spontaneous membrane fluctuations, as shown by the example recording traces from three different Apteronotus DL cells with different RMPs (Fig. 2A). A smaller number of $D L$ neurons were noisy, showing considerable spontaneous membrane fluctuations over approximately the same range of RMPs as the quiet cells (Fig. 2B). A histogram estimating the distribution of RMP variance (Fig. $2 C$ ) suggests that, in both Apteronotus and goldfish $D L$, there were distinct populations of quiet (variance $<0.5$ $\mathrm{mV}^{2}$ ) and noisy cells (variance $>0.5 \mathrm{mV}^{2}$ ).

\section{Noisy cells}

The noisy electrophysiological feature has previously been observed in pyramidal cells in the Apteronotus hindbrain ELL and has been attributed to the stochastic opening of voltage-gated ion channels, an effect which becomes stronger as the membrane potential increases toward threshold (Marcoux et al., 2016). We therefore wondered whether noisy DL cells shared these features. DL neurons displayed an in vitro RMPs that were relatively more hyperpolarized (Apteronotus: -70 to $-84 \mathrm{mV}$; goldfish: -66 to $-78 \mathrm{mV}$; Fig $2 D$ ), compared to the ELL pyramidal cells $(-67.8 \pm 5.7 \mathrm{mV}$, Berman and Maler, 1998) and neither subthreshold depolarizing, nor hyperpolarizing current steps altered the noise fluctuations of Apteronotus DL cells $(N=3$ noisy cells; Fig. $2 E)$. Additionally, we found that a more depolarized RMP of these noisy cells (Apteronotus, $N=6$ cells; goldfish, $N=4$ cells) was not associated with an increase in noise variance (Fig. $2 F$ ).

In some noisy cells, spontaneous membrane fluctuations could summate to cause a more sustained depolarization (Fig. $3 A$ ). The summating fluctuations were usually between 10 and $20 \mathrm{mV}$ in amplitude and often induced spontaneous action potentials as the membrane potential crossed the spike threshold. The duration of these spontaneous events was estimated to be $425.5 \pm 42.4 \mathrm{~ms}(N=4$ cells), and could reach as long as $800 \mathrm{~ms}$ in instances where spontaneous bursting occurred (Fig. 3B). We hypothesize that these events are caused by the summation of multiple postsynaptic potentials, as highlighted by the arrows in Figure $3 C$.

The intrinsic membrane noise of ELL pyramidal cells in the Apteronotus was shown to be unaffected by AMPA (CNQX) and NMDA (APV) receptor antagonists (Marcoux et al., 2016); this was expected given the lack of recurrent connections in ELL (Maler, 1979; Maler et al., 1981). In contrast, the application of kynurenic acid $(10 \mathrm{mM})$, a broad spectrum AMPA/NMDA-R antagonist, completely blocked the membrane potential fluctuations of DL cells
(Apteronotus: $N=3$; goldfish: $N=2$ cells; Fig. $3 D$ ); the average variance of the membrane potential decreased from $2.8 \pm 0.9$ to $0.10 \pm 0.04 \mathrm{mV}^{2}$ (paired $t$ test; $p=$ 0.0383 , row a, Table 3; Fig. $3 E$ ) while having a negligible effect on the average RMP (paired $t$ test; $p=0.7372$, row b, Table 3; Fig. 3F).

Based on these observations, we suggest that the DL cell membrane noise, are not generated by intrinsic conductances, but are instead primarily due to synaptic bombardment from neighboring cells within the DL recurrent network (Trinh et al., 2016). In our slice preparation, DL is disconnected from all extrinsic input (Giassi et al., 2012a, b). As such, the synaptic noise we observed in a subset of $\mathrm{DL}$ neurons provides evidence that the activity of the DL recurrent network alone can drive weak spiking activity. We do not currently know why only some neurons show pronounced membrane potential fluctuations.

\section{Quiet cells}

$R M P$, spike threshold, and spike discharge patterns

The RMPs of quiet Apteronotus DL cells were approximately Gaussian distributed with a mean of $-76.7 \pm 0.3 \mathrm{mV}$ $(N=29$ cells; Fig. $2 D)$, similar to that of goldfish $(-74.4 \pm 0.7$ $\mathrm{mV}, N=7$ cells). Using the hyperpolarized responses to negative current steps in the Apteronotus, we calculated an average membrane time constant of $10.28 \pm 0.24 \mathrm{~ms}$ for these neurons.

We next injected positive current steps to generate spiking. An example recording is shown in Figure $4 A i$, illustrating a typical DL neuron response in Apteronotus. The same response and spiking pattern was found in all cells regardless of their location within the Apteronotus $\mathrm{DL}$ region and was also observed in the goldfish DL (Fig. $4 B$ ). DL neurons exhibited very pronounced rectification: the membrane potential deflection in response to depolarizing current injections was far stronger than for hyperpolarizing currents of the same magnitude (Fig. 4Aii). This asymmetry is quantified below. In addition, we never observed any "sags" in the response of $\mathrm{DL}$ neurons to hyperpolarizing current injections, suggesting that they do not express hyperpolarization-activated cation channels $\left(l_{h}\right)$.

DL neurons discharge very few action potentials (Fig. $4 A, B)$ and the average injected current necessary to reach spike threshold (rheobase) was $38.17 \pm 2.52 \mathrm{pA}(N=15$ cells). Strong current injections $(70 \mathrm{pA})$ only resulted in average firing rates of $15.3 \pm 2.4 \mathrm{~Hz}(N=15$ cells $)$. We defined the spike threshold as the voltage corresponding to a pre-determined fraction of the maximal peak of the first derivative of the membrane potential response to current steps (Azouz and Gray, 2000; see Materials and Methods). Strong current injection in Apteronotus DL neurons typically results in an initial high-frequency burst of two or three spikes, followed by an irregular series of spikes separated by AHPs of varying amplitude and duration (Fig. $4 C, D$ ); the same pattern was also observed in the DL of goldfish (Figs. 4B, 5A). In Apteronotus, the threshold for the first spike is distributed with a mean of $-45.3 \pm 0.2 \mathrm{mV}(N=22$ cells) and has a high degree of overlap with the observed spike threshold for goldfish DL cells (mean: $-41.5 \pm 0.3 \mathrm{mV}, N=14$ cells; Fig. $4 E$ ). We 
A

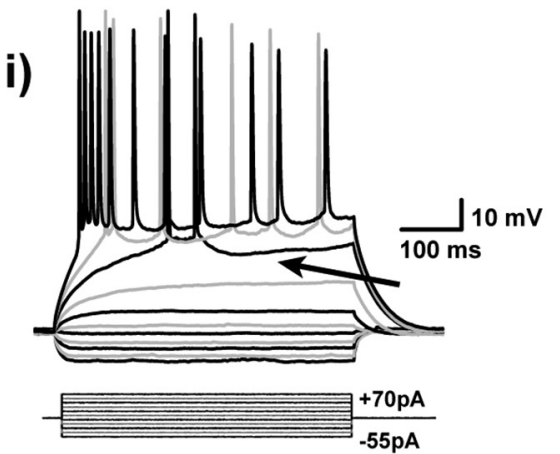

ii)

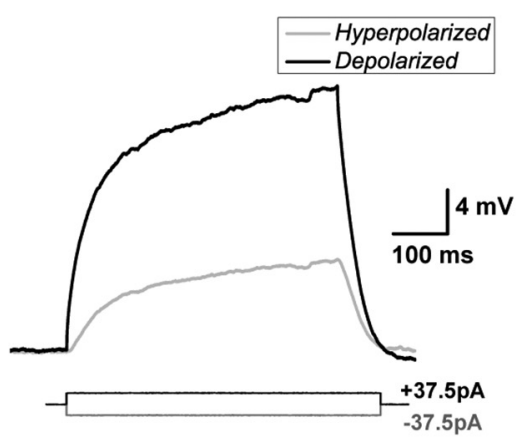

D
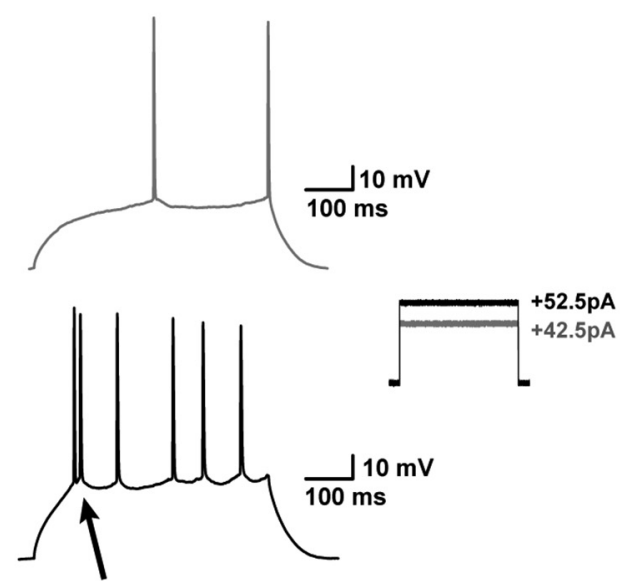

B

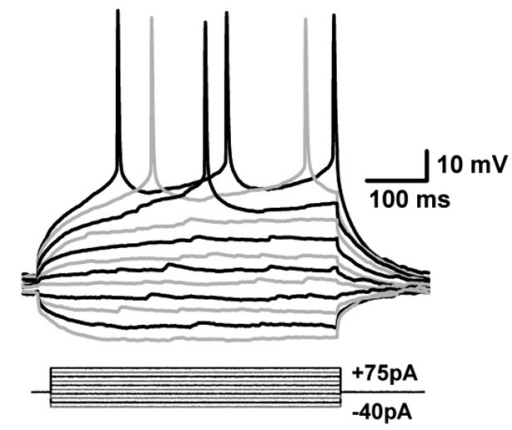

C

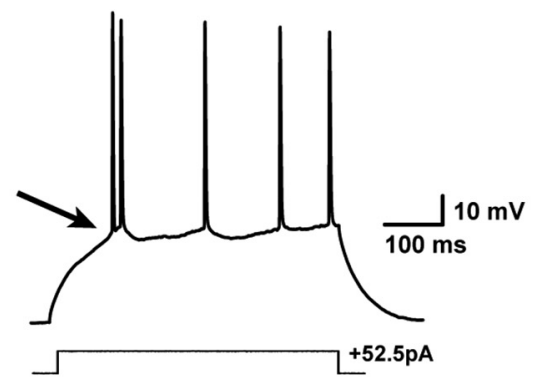

E

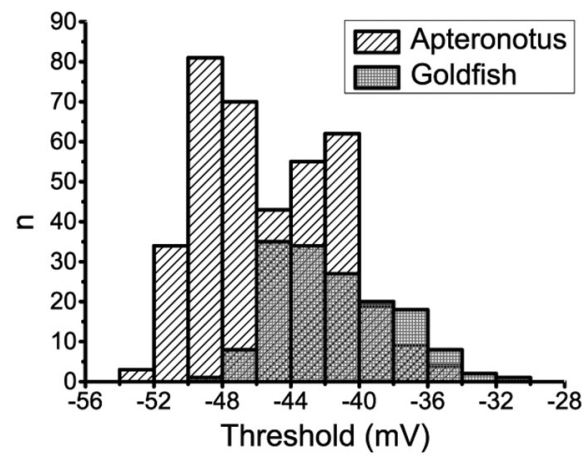

Figure 4. Spiking characteristics of DL neurons. $\boldsymbol{A} i$, Example of an Apteronotus DL quiet neuron response to the injection of $\pm 500-\mathrm{ms}$ current-steps with varying amplitudes as shown below the response traces. The latency to the first evoked spike clearly decreases with increasing current intensities. However, even at elevated current injections (+70 pA), these cells cannot be driven to a high firing rate (maximum in this case was $22 \mathrm{~Hz}$ ). This appears to be due, at least in part, to the prominent AHPs that follow the spikes (arrow). There is a large difference between the membrane potential responses to depolarizing versus hyperpolarizing current steps, much stronger responses are seen to positive current pulses. Aii, We illustrate this asymmetry by superimposing the absolute responses to equal intensity injections of a hyperpolarizing and subthreshold depolarizing current steps; the response to the hyperpolarizing step is inverted for a clear comparison. DL neuron recordings in goldfish also yielded a similar asymmetry and spiking patterns (data not shown; but see panel $\boldsymbol{B}$ ). $\boldsymbol{B}$, Example of a goldfish dorsal DL (DLd) neuron response to a standard 500 -ms current step injection; the region chosen for these recordings receive inputs from PG similar to the DL neurons in Apteronotus. The responses of these cells were very similar to those of Apteronotus DL neurons. C, Example recording of a DL neuron in response to a single current step injection. The arrow highlights the location of the threshold for these neurons (panel $\boldsymbol{E}$ ). $\boldsymbol{D} \boldsymbol{i}$, A single spike is evoked for currents near spike threshold. Dii, After current injections induce depolarizations exceeding the spike threshold, DL neurons emit a short doublet or triplet burst of spikes at a shorter latency (arrow, Apteronotus recording; similar behavior was seen in goldfish DL neurons). Note that spike amplitude drops slightly but progressively in the $\boldsymbol{C}, \boldsymbol{D}$ traces. $\boldsymbol{E}$, Histogram of the average threshold of the first current-evoked spike in $\mathrm{DL}$ neurons. The spike threshold, which was found using the first derivative of the membrane potential, was $\sim-45 \mathrm{mV}$ in Apteronotus and $\sim-42 \mathrm{mV}$ in goldfish. The total number of spikes across all cells used for these estimates was $n=380$ in Apteronotus and $n=154$ in goldfish. 
A

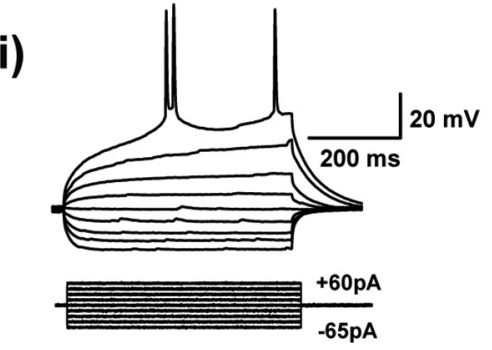

ii)

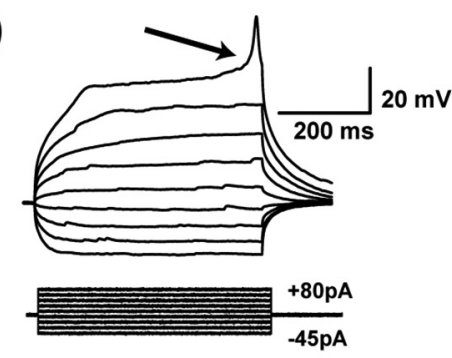

B

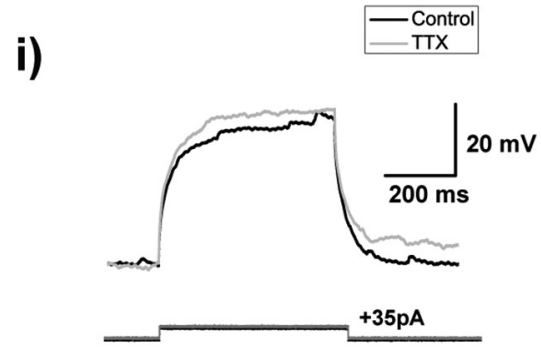

ii)

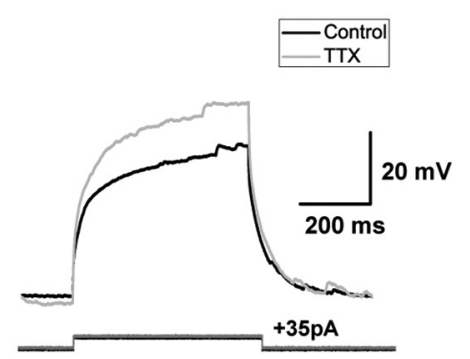

C i)

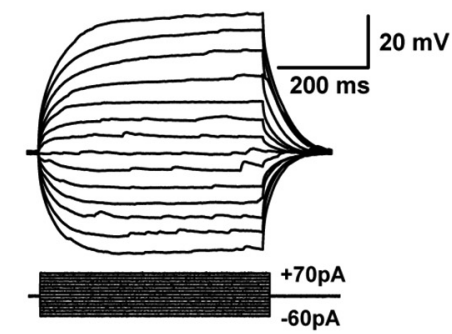

$20 \mathrm{mV}$

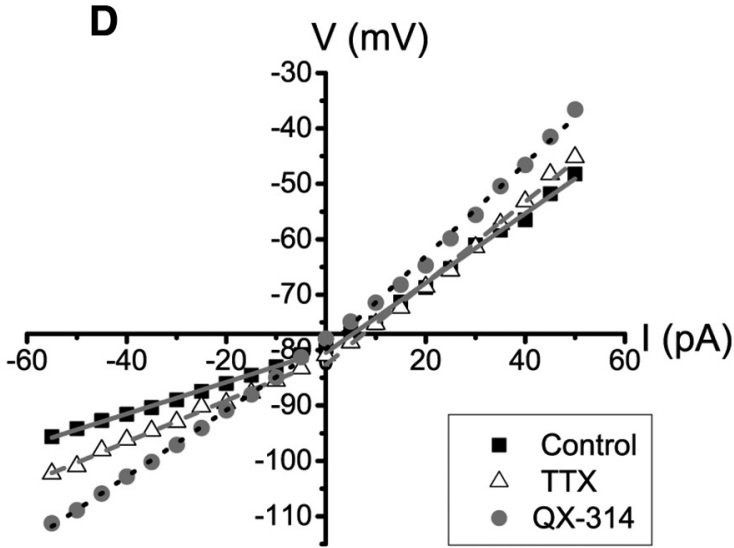

ii)

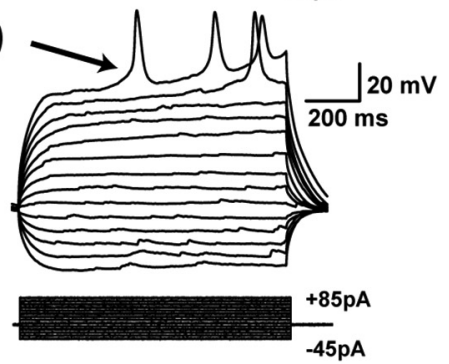

Figure 5. Pharmacological block of sodium and other channels in DL neurons. Ai, This panel illustrates a goldfish DL neuron's membrane potential response to $500-\mathrm{ms}$ current step injections. For $+60 \mathrm{pA}$, large spikes are evoked at a $-38.4-\mathrm{mV}$ threshold; in this example, the first spike has a height of $47.5 \mathrm{mV}$ from the threshold and has a half-width of $3.1 \mathrm{~ms}$. Aii, The bottom panel shows the responses after bath application of $20 \mu \mathrm{M}$ TTX, which completely eliminates the large fast spikes. Delayed, broad spikes (amplitude: $22.7 \mathrm{mV}$ from the threshold, half width: $10.5 \mathrm{~ms})$ are now evoked at elevated current levels $(+80 \mathrm{pA})$ with a spike threshold of -21.0 $\mathrm{mV}$. The arrow indicates the approximate location of the threshold for the broad TTX-insensitive spike. Bi, The response of a DL neuron to a current step at the subthreshold membrane potential before (black) and after (gray) application of TTX. After TTX treatment, the membrane potential did not dramatically change compared to control, and in some cases, (Bii) the subthreshold membrane potential was even more depolarized than in the control condition. Ci, Response of an Apteronotus DL neuron to current injection steps following QX-314 application via the recording pipette. Fast $\mathrm{Na}^{+}$spikes are eliminated by this treatment, even with strong current injections $(+70 \mathrm{pA}, 500 \mathrm{~ms})$ that would always evoke spiking in control neurons. Cii, Stronger current injection (+85 $\mathrm{pA}, 1000 \mathrm{~ms}$ ), evoked delayed broad spikes (amplitude from the threshold $=36.9 \mathrm{mV}$, half-width; $25.9 \mathrm{~ms}$ ) with a higher threshold $(-8.3 \mathrm{mV})$ compared to the TTX-insensitive spikes illustrated in panel Ai. Stronger current injections $(+85 \mathrm{pA}, 1000 \mathrm{~ms})$ evoked several putative $\mathrm{Ca}^{2+}$ spikes with a shorter latency to the first spike. The arrow highlights the approximate location of the threshold of the broad $\mathrm{Ca}^{2+}$ spike. $\boldsymbol{D}$, Average I-V relationship obtained from subthreshold Apteronotus and goldfish DL recordings without the application of any pharmacological blockers (black squares), after the application of $20 \mu \mathrm{M}$ TTX (white triangles), and with the inclusion of QX-314 within the patch pipette solution (gray circles). Both the curves for control and TTX are piecewise linear with the slope being markedly smaller for hyperpolarizing (control; $0.28 \pm 0.02 \mathrm{mV} / \mathrm{pA}$, TTX; $0.32 \pm 0.04 \mathrm{mV} / \mathrm{pA}$ ) compared to depolarizing steps (control; $0.69 \pm 0.03 \mathrm{mV} / \mathrm{pA}$, TTX; $0.74 \pm 0.03 \mathrm{mV} / \mathrm{pA}$ ). In contrast, the addition of QX-314 has linearized the I-V curve (hyperpolarizing slope $=0.60 \pm 0.11 \mathrm{mV} / \mathrm{pA}$, depolarizing slope $=0.86 \pm 0.12 \mathrm{mV} / \mathrm{pA}$ ) with its main effect on the response to hyperpolarizing current injections (Table 1). Extended information illustrating the expression of GIRK channels in the Apteronotid fish's brain is available in Extended Data Figure 5-1. 
measured the mean spike peak amplitude from both the membrane potential at spike threshold (Apteronotus: 66.2 $\pm 1.0 \mathrm{mV}, N=22$ cells; goldfish: $50.8 \pm 1.0 \mathrm{mV}, N=14$ cells) and from the RMP (Apteronotus, $95.9 \pm 0.5 \mathrm{mV}$; goldfish, $90.6 \pm 0.5 \mathrm{mV}$ ). Lastly, we also measured the spike half-width at half-maximum (Apteronotus: $2.3 \pm 0.1$ ms; goldfish: $3.7 \pm 0.3 \mathrm{~ms}$ ).

In summary, the core biophysical properties of DL cells receiving PG input in Apteronotus and goldfish (dorsal DL, non-olfactory; Northcutt, 2006; Yamamoto and Ito, 2008) were similar, DL neurons have a hyperpolarized RMP and a high spike threshold and spike only sparsely in response to even strong current injection.

\section{Asymmetric input resistance}

A striking property of Apteronotus and goldfish DL cells is an asymmetry in their response to hyperpolarizing versus depolarizing current steps (Fig. 5Ai). In ELL pyramidal cells, an equivalent, though far smaller asymmetry is caused by a persistent $\mathrm{Na}^{+}$channel (Turner et al., 1994) that amplifies excitatory synaptic input (Berman et al., 2001). We tested this possibility by blocking the sodium channels of DL neurons with a local application of $20 \mu \mathrm{M}$ TTX (control: $N=18$ cells, TTX: $N=6$ cells). As expected, spike discharge at the previous threshold $(\sim-45 \mathrm{mV})$ was completely blocked by TTX (Fig. 5Aii); the small highthreshold spikes evoked with much stronger current injections will be discussed below (Fig. 5Aii,Cii). On closer inspection of the neurons' response to positive current injections, we found that application of TTX did not dramatically change their depolarizing ramp response to peri-threshold current injection (Fig. 5Bi) and, in some cases, would even slightly increase the neuron's response to positive current injections (Fig. 5Bii). These data indicate that low threshold persistent sodium channels are likely not (or only weakly) expressed in DL neurons.

We next plotted the average I-V curves for negative and positive (subthreshold) current injection (Apteronotus and goldfish; Fig. 5D). The stronger response to positive versus negative current injection can be clearly seen in the rectification of the I-V curve for the control condition. These curves can be used to compute separate input resistances for positive and negative current injections. Typically, the response to hyperpolarizing current injection is assumed to reflect the passive properties of a neuron and is reported as its input resistance (e.g., ELL pyramidal cells; Mathieson and Maler, 1988; Berman et al., 1997). In DL cells, the input resistance for depolarizing current injection is approximately double that for hyperpolarizing current injection when compared under both control and TTX conditions (Table 1; paired $t$ test; control; $p=3.3 \times 10^{-12}$, row c, Table 3, TTX; $p=9.9 \times$ $10^{-6}$, row $\mathrm{d}$, Table 3 ). The addition of TTX had no significant effect on the hyperpolarizing slope (one-way ANOVA; $p=0.32$, row $f$, Table 3 ), nor did it have any significant effect on the input resistance for the depolarizing slope (Table 1; one-way ANOVA; $p=0.42$, row $\mathrm{h}$, Table 3; Fig. $5 D$ ). Thus, it appears that there is no contribution of persistent $\mathrm{Na}^{+}$channels to the RMP of DL
Table 1. I-V slope measurements obtained from the depolarizing and hyperpolarizing responses of DL neurons in both teleost species for the TTX and QX-314 experiments

\begin{tabular}{lcc}
\hline \multicolumn{1}{c}{ Conditions } & $\begin{array}{c}\text { Depolarizing } \\
\text { slope }(\mathrm{G} \Omega)\end{array}$ & $\begin{array}{c}\text { Hyperpolarizing } \\
\text { slope }(\mathrm{G} \Omega)\end{array}$ \\
Control $(N=18$ cells $)$ & $0.69 \pm 0.03$ & $0.28 \pm 0.02$ \\
TTX $(N=6$ cells $)$ & $0.74 \pm 0.03$ & $0.32 \pm 0.04$ \\
QX-314 $(N=6$ cells $)$ & $0.86 \pm 0.12$ & $0.60 \pm 0.11$ \\
\hline
\end{tabular}

neurons, in accordance with the small effects of $\Pi \mathrm{TX}$ observed in Figure $5 B$.

To further investigate the basis of the observed asymmetrical response to current injection, we have also recorded DL neurons using an intracellular solution containing $5 \mathrm{mM}$ QX-314, a blocker of $\mathrm{Na}^{+}$channels, as well as some $\mathrm{K}^{+}$and $\mathrm{Ca}^{2+}$ channels (Talbot and Sayer, 1996; control, $N=18$ cells; $Q X-314, N=6$ cells; Fig. $5 C, D)$. QX-314 has previously been used to block all $\mathrm{Na}^{+}$ channels in Apteronotus ELL pyramidal cells (Berman et al., 2001). The I-V graph constructed from the QX-314 experiments showed a higher depolarizing versus hyperpolarizing input resistance (paired $t$ test; $p=2.3 \times 10^{-4}$, row e, Table 3), similar to control and TTX conditions (above). There was a small increase in input resistance for the depolarizing current injection that failed to reach significance (Table 1; one-way ANOVA, $p=0.07$, row i, Table 3; Fig. 5D). In contrast, there was a large and highly significant increase of input resistance in the responses to hyperpolarizing current injections, it more than doubled over control values (Table 1; one-way ANOVA, $p=5.9 \times$ $10^{-5}$, row $\mathrm{g}$, Table 3 ). Since we only expect $\mathrm{K}^{+}$permeating channels to be open at such hyperpolarized membrane potential, we attribute this effect to the "nonspecific" actions of QX-314 (Perkins and Wong, 1995; Slesinger, 2001). The results of the TTX and QX-314 experiments lead to two hypotheses: first, the subthreshold response of $D L$ cells to depolarizing input is mainly due to their passive membrane properties. Second, the RMP of hyperpolarized DL cells is likely due to a strong rectifying $\mathrm{K}^{+}$conductance that is blocked by QX-314 and typically prevents the cell from deviating from the reversal potential of $\mathrm{K}^{+}$ions (Fig. 5). Given that GIRK channels are ubiquitous in the mammalian cortex (Lüscher and Slesinger, 2010; Luján and Aguado, 2015) and can be blocked by QX-314 (Zhou et al., 2001), we suspected them to also be present in the teleost pallium. To confirm the presence of GIRKs in DL, we used a RT-PCR approach to show the expression of GIRK channels in different brain regions in the Apteronotid fish (DL, subpallium, tectum/torus, cerebellum, ELL and hindbrain) using a primer pair hybridizing in conserved segments of all GIRK paralogs. Unsurprisingly, pan-GIRK amplicons were found in all brain regions, but were not present in the control (Extended Data Fig. 5-1), suggesting that GIRK channels are ubiquitously expressed in the Apteronotus brain.

\section{Voltage-dependent calcium conductance}

In the presence of TTX, strong current injections ( $>80$ pA) were able to evoke a broad (half-width: $33.0 \pm 3.1 \mathrm{~ms}$ ) 
A

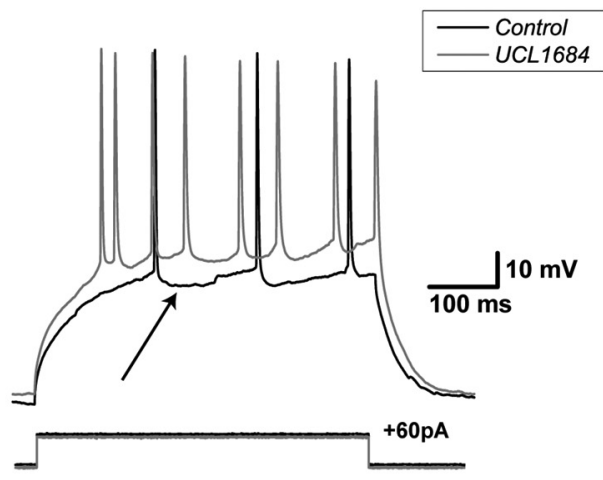

C

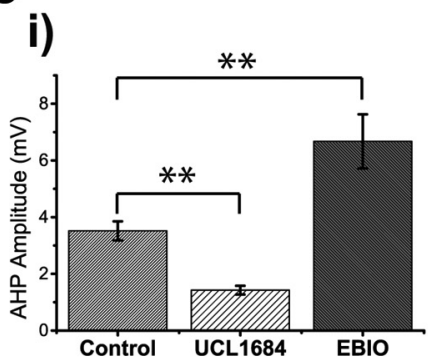

ii)

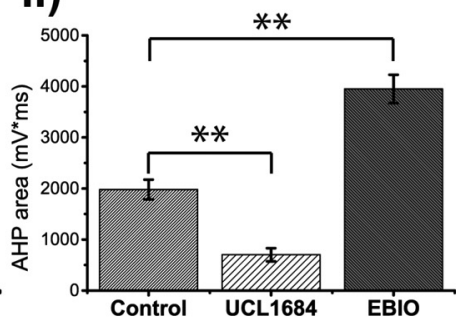

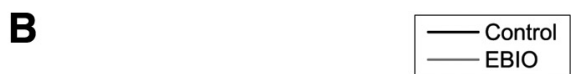

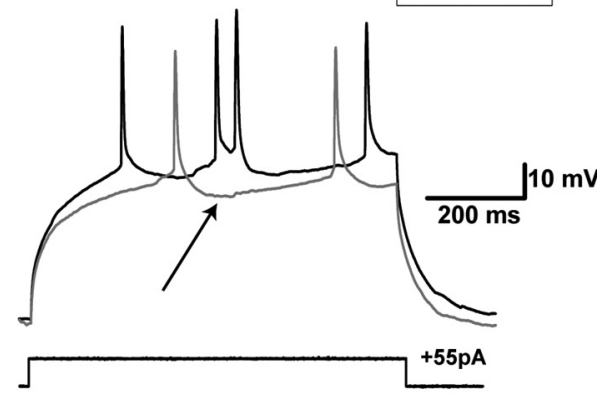

D

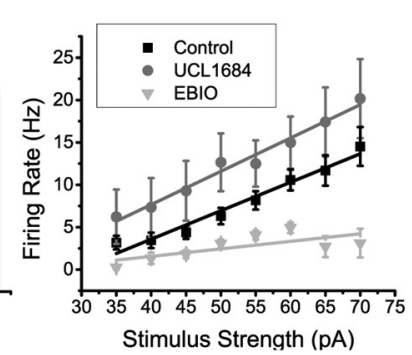

Figure 6. SK-mediated potassium channels contribute to the AHP of DL neurons. A, Apteronotus DL neuron response to 500-ms step current injection before (black trace) and after the bath application of $30 \mu \mathrm{M}$ UCL1684 (gray trace). The black arrow shows the minimum membrane potential between two spikes and is used to estimate the amplitude of the AHP by comparison with the membrane potential immediately preceding the first action potential. The prominent AHPs seen in the control condition are reduced by this treatment and the spike rate has also increased (from three to eight spikes). $\boldsymbol{B}$, DL neuron response to the injection of 750 -ms current steps before (black trace) and after bath application of $1 \mathrm{mM}$ EBIO in the goldfish (gray trace; a longer pulse was needed to increase the likelihood of evoking more than one spike). The amplitude of the AHP (arrow) was increased by this treatment and the spike rate has been reduced (from 4 to $2 \mathrm{~Hz}$ ). C, Average amplitude (i) and average area under the membrane potential (ii) of the AHP following the first spike of DL neurons in response to current steps (control, $N=12$ cells; UCL1684, $N=7$ cells; EBIO, $N=6$ cells). Both the amplitude and the area under the AHP are significantly diminished after the application of UCL1684, while a strong increase was observed after the application of EBIO. D, Average firing rate plotted as a function of the amount of current injected for the control condition (black trace), the UCL1684 condition (gray trace), and the EBIO condition (light gray trace) in both Apteronotus and goldfish (control, $N=28$ cells; UCL1684, $N=7$ cells; EBIO, $N=6$ cells). The firing rate increases for all current injections after UCL1684 application, while the firing rate decreases after the EBIO application. $* * p<0.01$.

spike with a very high threshold (mean threshold: $-21.2 \pm$ $0.5 \mathrm{mV}, N=4$ of 6 cells; Fig. 5Aii). Spike amplitude was $18.6 \pm 0.7 \mathrm{mV}$ from the threshold potential and $79.1 \pm 0.9$ $\mathrm{mV}$ from the RMP. Similar to the TTX results, QX-314 treated cells did not produce any action potentials at the threshold for control cells (Fig. 5Ci), but did produce broad spikes at much higher stimulus intensities (spike half-width, $21.1 \pm 1.1 \mathrm{~ms}$; height $=31.3 \pm 0.7 \mathrm{mV}$ from threshold and $100.6 \pm 0.9 \mathrm{mV}$ from RMP, $N=4$ of 6 cells; Fig. 5Cii). The average threshold for these broad spikes was found to be at $-6.8 \pm 1.3 \mathrm{mV}$, which is also consistent with the range of voltages that has been reported for the activation of $\mathrm{HVA} \mathrm{Ca}^{2+}$ channels (Tsien et al., 1988). Therefore, we hypothesize that DL neurons express HVA $\mathrm{Ca}^{2+}$ channels that will likely be activated by $\mathrm{Na}^{+}-$ mediated action potentials.

\section{AHPs}

DL neurons exhibit a strong AHP (Figs. 4-6). Previously, it was shown that DL cells express both SK1 and SK2 channels (Ellis et al., 2008) and that UCL1684 is highly effective at blocking such channels (Harvey-Girard and
Maler, 2013). We therefore bath-applied $30 \mu \mathrm{M}$ UCL1684, resulting in a significantly diminished AHP compared to the control conditions (Fig. 6A). To quantify this AHP reduction, we measured the AHP amplitude (Fig. $6 \mathrm{C} i$ ) and the area under the AHP (Fig. 6Cii) following the first single spike obtained in response to current injection. The addition of UCL1684 reduced the average amplitude of the first AHP to half its control value (control: $3.5 \pm 0.3 \mathrm{mV}, N$ $=13$ cells; UCL1684: $1.4 \pm 0.2 \mathrm{mV} ; N=7$ cells; twosample $t$ test; $p=0.0003$, row j, Table 3; Fig. 6Ci). A similar reduction was also observed when comparing the area under AHPs: from $1980.3 \pm 192.6$ to $701.4 \pm 128.4$ $\mathrm{mV} / \mathrm{ms}$ (two-sample $t$ test; $p=0.0002$, row I, Table 3; Fig. 6 Cii). In contrast, after the addition of the SK channel agonist EBIO (1 mM; Ellis et al., 2007), current injection evoked very few spikes; thus current steps were increased to 750 and $1000 \mathrm{~ms}$. As expected, the average AHP amplitude increased from $3.5 \pm 0.3 \mathrm{mV}$ to $6.7 \pm 1.0$ $\mathrm{mV}$ (control, $N=13$ cells; EBIO, $N=6$ cells; two-sample $t$ test; $p=0.001$, row $\mathrm{k}$, Table 3), while the area under the curve also increased from $1980.3 \pm 192.6$ to $3952.2 \pm$ 
A

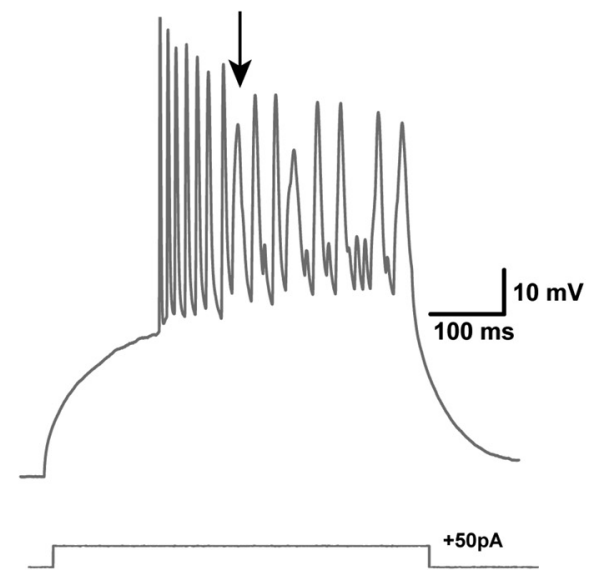

C

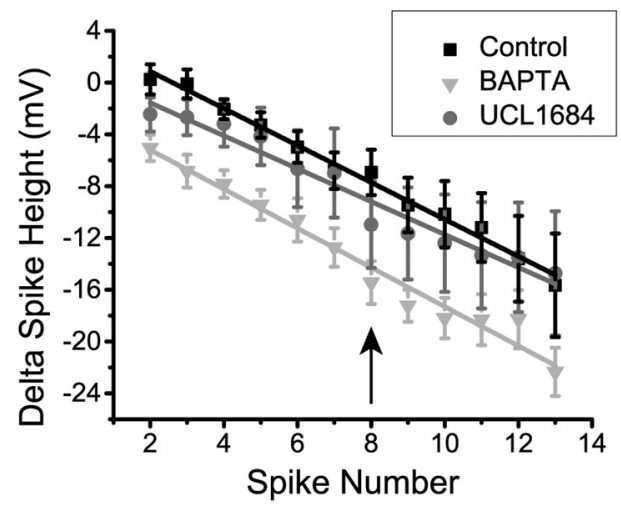

B

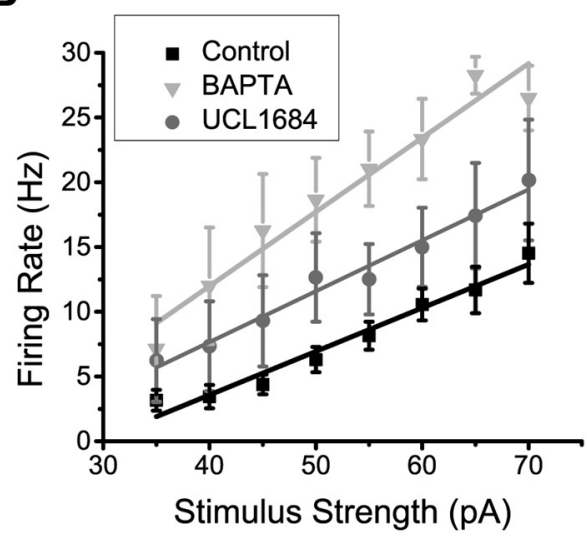

D

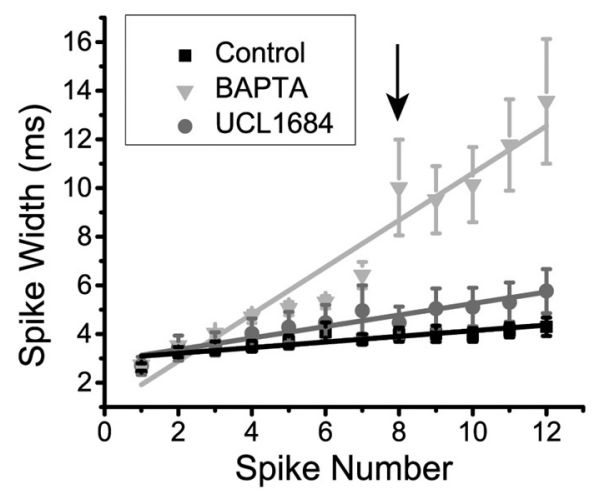

Figure 7. The effect of intracellular $\mathrm{Ca}^{2+}$ chelation on $\mathrm{DL}$ neuron responses to depolarization. $\boldsymbol{A}$, Example recording trace (Apteronotus) with $10 \mathrm{mM}$ BAPTA added to the internal solution of the patch pipette. The AHP appears to be completely eliminated which promotes higher frequency spiking; note that successive spike heights drop continuously for the first seven spikes. By the 8th spike, very prominent spike broadening begins and the spike height drops to an even greater degree compared to the UCL1684 application in Figure 6 A. B. The average firing rate was plotted as a function of the amount of current injected for the control (black trace, $N=28$ cells), UCL1684 (gray trace, $N=7$ cells), and BAPTA conditions (light gray trace, $N=7$ cells). The addition of intracellular BAPTA promotes an even stronger increase in firing rate compared to the addition of the SK channel blocker UCL1684. $\boldsymbol{C}$, The average difference in spike height between the $n$th spike and the first spike was plotted as function of successive spikes obtained after a 500-ms current step injection for all three conditions mentioned in $\boldsymbol{B}$. The addition of UCL1684 did not strongly affect the spike height, unlike the addition of BAPTA, which reduced the spike height across successive spikes following a step current injection. The arrow highlights the 8th spike, which marks the beginning of the non-linearity in the BAPTA condition. $\boldsymbol{D}$, The average spike width was plotted as a function of successive spikes, similar to panel $\boldsymbol{C}$. UCL1684 application has only a minimal effect on spike width. The presence of intracellular BAPTA increased the spike width across successive spikes during a step current injection when compared to the other conditions. The arrow indicating the 8th spike marks a strong change in spike width, as denoted by the arrow in $\boldsymbol{A}$.

$277.5 \mathrm{mV} / \mathrm{ms}$ (two-sample $t$ test, $p=0.00002$, row $\mathrm{m}$, Table 3).

Blocking SK channels also increased the currentevoked firing rate compared to the control condition (control, $N=28$ cells; UCL1684, $N=7$ cells; two-way ANOVA; $p=0.0013$, row $n$, Table 3; Fig. $6 D$ ), while EBIO reduced the evoked firing rate since the cell required a longer time to reach spike threshold after the first spike ( $N=6$ cells; two-way ANOVA; $p=0.000092$, row o, Table 3; Fig. $6 B, D)$. We conclude that the SK1/2 channels of DL neurons act as negative feedback on the cell's responsiveness to excitatory input.

Finally, we wanted to confirm whether SK channel activation in DL neurons could be blocked by preventing $\mathrm{Ca}^{2+}$ activation of the channel. We recorded DL neurons in Apteronotus using an intracellular solution containing 10 mM BAPTA, a $\mathrm{Ca}^{2+}$ chelator ( $N=7$ cells; Fig. $7 A$ ). In all cases, the AHP was completely abolished, unlike the partial AHP block obtained with UCL1684. This suggests that another unidentified $\mathrm{Ca}^{2+}$-activated $\mathrm{K}^{+}$channel may also be contributing to the AHP. Further work will be required to investigate this possibility. The firing rate also dramatically increased compared to the control condition (control, $N=28$; UCL1684, $N=7$; BAPTA, $N=7$ cells; two-way ANOVA; $p=1.5 \times 10^{-15}$, row $p$, Table 3; Fig. 7B) and compared to UCL1684 treatment (two-way ANOVA; $p$ $=0.00063$, row $\mathrm{q}$, Table 3). Furthermore, this BAPTAinduced increase in firing rate was also accompanied by a significant reduction in spike height compared to both control (two-way ANOVA; $p=2.1 \times 10^{-12}$, row r, Table 3; 

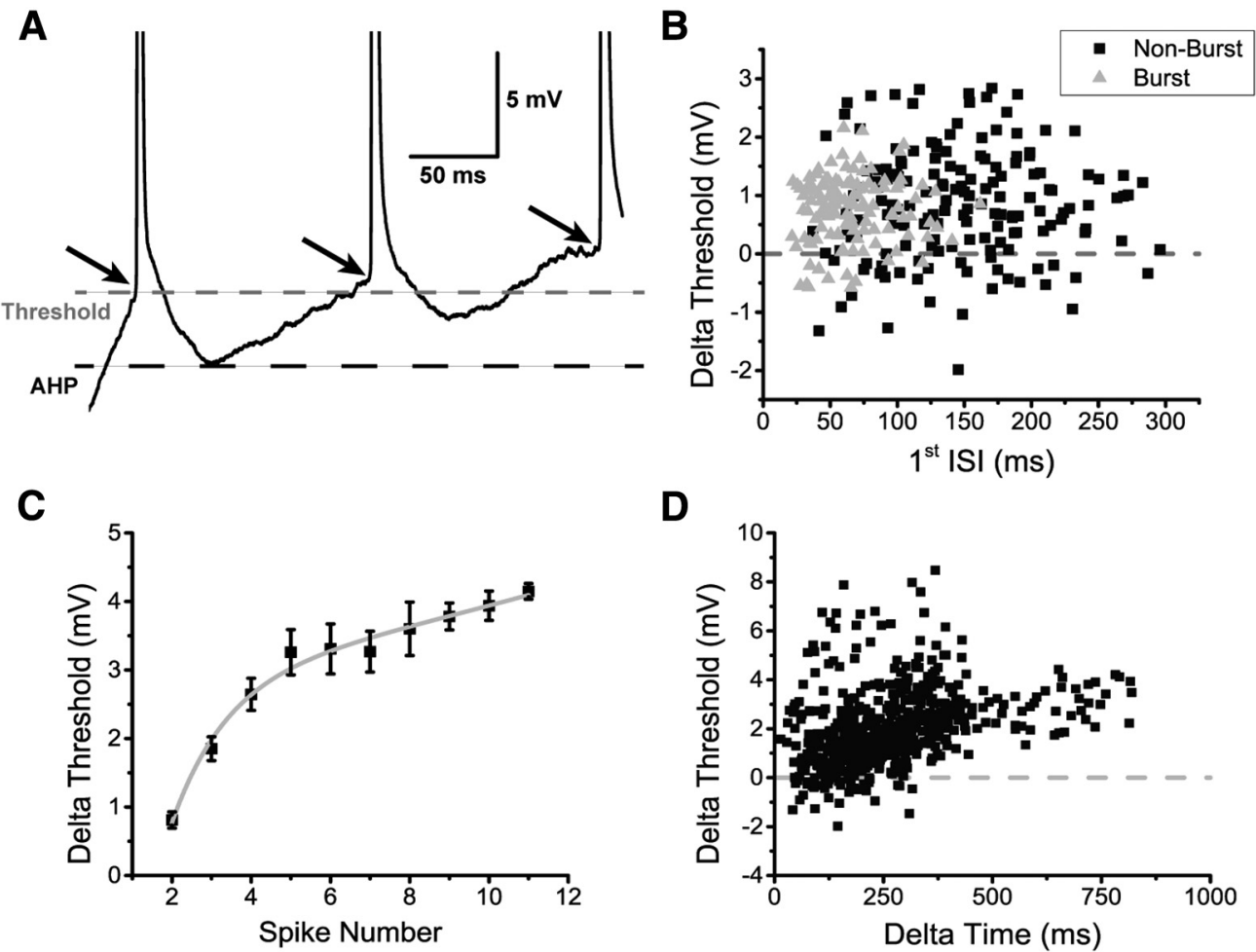

Figure 8. DL neuron spiking causes a decrease in AHP amplitude and an increase in spike threshold. $\boldsymbol{A}$, A magnified view of the first three spikes in an example trace of a DL neuron's response to a $+60-p A$ current injection where the black dashed line is placed to coincide with the minimum of the first spike's AHP and the gray dashed line is placed to coincide with the first spike's threshold. The black arrows highlight the progressive increase in spike threshold following consecutives spikes. $\boldsymbol{B}$, The increase in spike threshold between the second and first spikes was plotted in the same manner as a function of the first ISI. Individual black squares represent a pair of spikes that were taken from a trace which did not contain an initial burst (total of 160 non-burst pairs), while individual gray triangles represent a pair of spikes that were taken from a trace displaying an initial burst of spikes as in Figure $4 \mathrm{C}$ (total of 117 burst spike pairs). The majority of the spike thresholds increased (>300 ms) with no evident recovery. $\boldsymbol{C}$, The difference in average spike threshold between the $n$th spike and the first spike is plotted as a function of the spike number. The subsequent curve was fit with a double exponential equation $\left(\mathrm{y}=2.72 e^{0.04 x}-9.0 e^{-0.72 x} ; R^{2}=0.987\right)$. $\boldsymbol{D}$, The increase in spike threshold between the $n$th spike and the first spike is plotted as a function of the time interval between them. Each black square represents a spike pair (total of 573 spike pairs). Overall, the increase in threshold appears to be larger following longer timer intervals. Extended information related to the modulation of the AHP after prolonged spiking is available in Extended Data Figure 8-1.

Fig. 7C) and UCL1684 conditions (two-way ANOVA; $p=$ $1.6 \times 10^{-6}$, row $\mathrm{s}$, Table 3 ). In contrast, the difference in spike height between the UCL1684 and control did not yield a significant difference (two-way ANOVA; $p=0.14$, row $\mathrm{t}$, Table 3). We hypothesize that $\mathrm{Na}^{+}$channel inactivation may be causing this reduction (see below in the Dynamic AHP and spike threshold section). Another distinctive feature of the DL neuron's spiking response during the BAPTA application was the increase in spike width occurring along successive spikes and typically becoming most prominent by the $8^{\text {th }}$ spike (Fig. $\left.7 A, D\right)$. In the control and UCL1684 conditions, there was a slight increase in spike width, however, in the BAPTA condition, the spike width increased dramatically with successive spikes (Fig. $7 A, D$ ) compared to control (two-way ANOVA; $p=1.3 \times$ $10^{-31}$, row u, Table 3 ) and UCL1684 conditions (two-way ANOVA; $p=3.7 \times 10^{-10}$, row $v$, Table 3 ). In contrast, the difference between the control and BAPTA conditions was not significant up until the third spike (two-way ANOVA; $p=0.24$, row $w$, Table 3 ), suggesting that the spike width increase is caused by a cumulative process.
Calcium channels typically inactivate via a $\mathrm{Ca}^{2+}$-dependent mechanism (Simms and Zamponi, 2014), leading us to hypothesize that this dramatic change in spike width may be caused by a decrease in $\mathrm{Ca}^{+}$-dependent inactivation of the $\mathrm{Ca}^{2+}$ channel leading to an increase of its open time.

\section{Dynamic AHP and spike threshold}

Although the presence of the AHP greatly reduces the firing rate, we also observed that after successive spikes, the AHP itself decreased (Extended Data Fig. 8-1A) and the spike threshold increased (Fig. $8 A$ ). To better quantify the AHP modulation, we measured the difference in AHP amplitude between the first two spikes of a current-evoked spike train that did not show an initial burst. We found that there was a significant reduction in AHP amplitude that was invariant to the time length of the AHP $\left(N=26\right.$ cells; one-sample $t$ test, $p=4.45 \times 10^{-27}$, row x, Table 3; Extended Data Fig. 8-1B, black squares). For recording traces that showed initial bursts, we examined the first spike pair following the burst and found a 
similar reduction in AHP ( $N=20$ cells; one sample $t$ test, $p=1.26 \times 10^{-13}$, row y, Table 3; Extended Data Fig. $8-1 B$, gray triangles). This reduction is presumably caused by $\mathrm{Ca}^{2+}$-induced inactivation of the $\mathrm{HVA} \mathrm{Ca}^{2+}$ channels, which will decrease the total amount of $\mathrm{Ca}^{2+}$ available to the cell and limit the activation of SK channels.

Even with the spiking-induced reduction of the AHP, DL neurons could not surpass a sustained firing rate of $30 \mathrm{~Hz}$ (Fig. 7B), which suggests the presence of an additional mechanism(s) that limits firing rate. In ELL pyramidal neurons, spike threshold fatigue has been shown to limit the firing rate whenever a burst occurs (Chacron et al., 2007). On closer inspection, we found a significant increase in spike threshold during long spike trains (Fig. 8A). This dynamic spike threshold was also found to be invariant to the ISI (up to $\sim 300 \mathrm{~ms}$ ) for both non-burst traces (onesample $t$ test, $p=1.24 \times 10^{-22}$, row z, Table 3; Fig. $8 B$, black squares) and for traces containing an initial burst (one sample $t$ test, $p=8.30 \times 10^{-28}$, row aa, Table 3; Fig. $8 B)$. Next, we wanted to confirm whether the threshold fatigue that was observed in DL neurons may be caused by the history of past spikes, i.e., whether $\mathrm{Na}^{+}$channel inactivation due to continuous spiking may influence the spike threshold. We examined the difference in threshold for all non-burst traces to see whether it varies throughout a spike train. The threshold increases continued to at least 10 spikes and could be fitted by a double exponential function (equation: $y=2.72 e^{0.04 x}+-9.0 e^{-0.72 x} ; R^{2}=$ 0.987; Fig. $8 C$ ); here we considered only the number of spikes and not the duration of the spike train. A similar analysis where the difference in threshold was compared to the time between spikes instead of the spike number also led to the same conclusion: this effect became more prominent after long periods of depolarization despite the variability in the number of intervening spikes (Fig. $8 D$ ). These results suggest that the increase in threshold is caused by an accumulation of slow $\mathrm{Na}^{+}$channel inactivation.

In mammalian cortical cells, the recovery from inactivation of $\mathrm{Na}^{+}$channels have both a fast component (millisecond timescale) and a slow component that can extend to much longer timescales (seconds to minutes; Fleidervish et al., 1996; Mickus et al., 1999; Ellerkmann et al., 2001). To quantify the duration of this spike threshold adaptation, we developed a protocol in which a long ramp current (evoking multiple spikes) was injected followed by a shorter ramp current (evoking one spike) at various inter-stimulus time intervals (Fig. 9A, upper panel). This protocol induced spike threshold fatigue during the first current injection, while the second current injection was used to test for time-dependent changes in spike threshold. We found that the increase in spike threshold between the first and second current injection was significantly higher at short compared to longer time intervals (Fig. 9A, bottom panel). Using these changes in threshold, we found that the recovery from this spike threshold fatigue had a highly variable time constant ranging from 300 to $900 \mathrm{~ms}$ with an average time constant $\tau_{\exp }=$
$637.28 \pm 85.9 \mathrm{~ms}$ (Fig. 9B). This suggest that the decrease in cell excitability caused by the dynamic threshold can operate on the timescale of hundreds of milliseconds.

To further investigate whether $\mathrm{Na}^{+}$channel inactivation is responsible for the observed increase in threshold, we employed a model with minimal assumptions: the iEIF (Platkiewicz and Brette, 2011). This model includes a slow inactivation term, as well as the traditional fast inactivation term associated with $\mathrm{Na}^{+}$channels; inactivation kinetics for both forms were derived from our data (see Materials and Methods). Since we were primarily interested in the effect of sodium inactivation on the spike threshold, the minimal model omits AHP dynamics and $\mathrm{Ca}^{2+}$ currents (see Materials and Methods). We found that the addition of slowly inactivating $\mathrm{Na}^{+}$channels, as suggested by the effects of BAPTA (Fig. 7A), was itself sufficient to qualitatively reproduce the response of DL neurons to current injection and predict an increase in spike threshold that was similar to that observed in our whole-cell recordings (Fig. 9C). We therefore conclude that the accumulation of slow $\mathrm{Na}^{+}$channel inactivation, caused by spike discharge and simple depolarization, may act as a source of negative feedback to reduce the cell's firing rate via an increase in spike threshold.

\section{Discussion}

The work presented here is, to our knowledge, the first study of the biophysical properties of teleost DL neurons. Our previous work mapped the local DL circuitry (Trinh et al., 2016), the organization of thalamic and other inputs to DL (Giassi et al., 2012b), and the telencephalic connectivity of DL (Giassi et al., 2012a; Elliott et al., 2017). In gymnotiform fish, we have previously shown that the electrosensory system contributes to spatial learning (Jun et al., 2016), and that the PG (thalamic) inputs to $D L$ can encode responses to object motion (Wallach et al., 2018). Although the intrinsic and extrinsic properties of DL synaptic input have yet to be examined, we believe that the constraints imposed by DL circuitry, behavioral function plus recent theoretical analyses, are sufficient to generate testable hypotheses of the computations performed by $\mathrm{DL}$ during spatial learning. Below, we first summarize the main conclusions of our work and then discuss whether the biophysical properties of DL neurons and their connectivity are compatible with the critical role of $\mathrm{DL}$ in spatial learning and memory. In particular, we suggest that $\mathrm{DL}$ neurons possess the minimal requirements to be labeled as sparse coders. Next, we suggest that spike threshold adaptation is key to the extraction of spatial information in $D L$ from the time stamped electrosensory input conveyed by PG (Wallach et al., 2018). Our hypothesis relies on a previous theoretical model of time coding cells (Itskov et al., 2011) that utilizes, as an essential ingredient, spike threshold adaptation with a long recovery time constant.

Our main results show that DL neurons express a combination of ion channels that have been reported for many other types of neurons. DL neurons have a hyperpolarized RMP. We hypothesize that this is due, at least in part, to GIRK channels. GIRKs can hyperpolarize mammalian CA1 
A i)

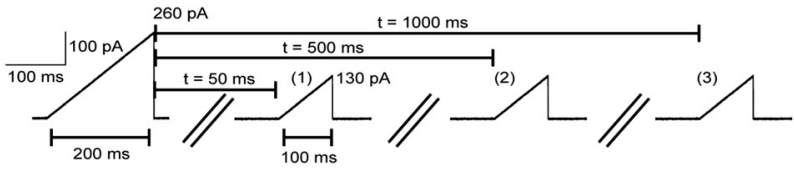

ii)

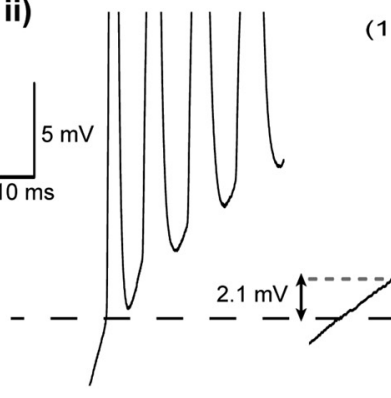

(1)

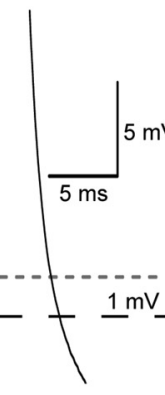

B

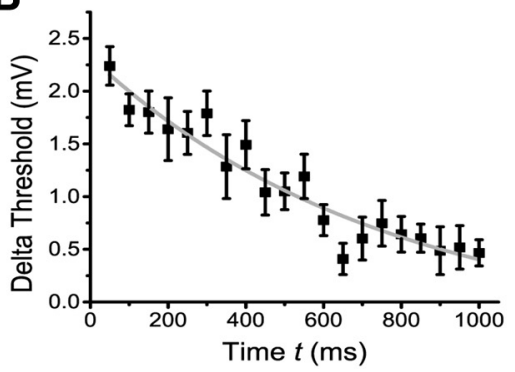

(2)

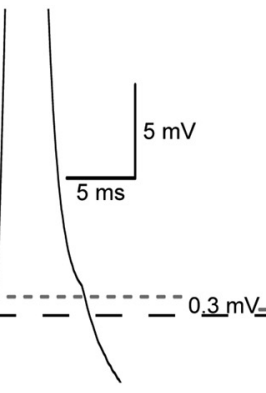

(3)

C i)

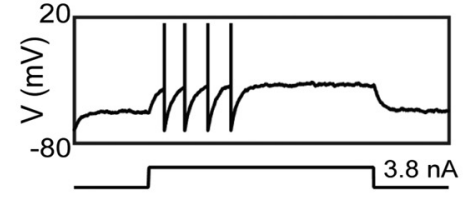

ii)

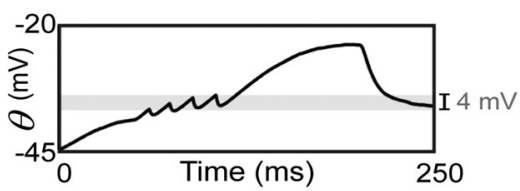

Figure 9. DL neuron spike threshold adaptation can last up to hundreds of milliseconds. $\boldsymbol{A i}$, Two ramp current injections separated at various times $t$ (in this example 50,500, and $1000 \mathrm{~ms}$ ) were used to measure the time constant of the spike threshold adaptation. Although both ramp current injections have the same slope (slope $=1.3 \mathrm{pA} / \mathrm{ms}$ ), the objective of the first ramp current was to induce an accumulation of $\mathrm{Na}^{+}$channel inactivation through the firing of multiple action potentials and therefore was stronger than the second ramp current which would only produce one action potential. Aii, A magnified view of the example responses obtained after the first ramp current injection and after the second ramp current injections at times $t=50 \mathrm{~ms}, t=500 \mathrm{~ms}$, and $t=1000 \mathrm{~ms}$, respectively. The black dash line is aligned to the first spike's threshold obtained after the first ramp current injection while the gray dotted lines are aligned to the spike threshold obtained from the second ramp current injection for the various times $t$ mentioned previously. $\boldsymbol{B}$, The average difference in spike threshold (for the first spike only) between the first and second ramp current injections were plotted as a function of the time $t$ between each ramp injection. The resulting curve was fitted with an exponential equation ( $\left.\mathrm{y}=2.38 * e^{-0.0017 x}, R^{2}=0.917\right)$. $\boldsymbol{C}$, We used a simplified EIF with fast $\left(\tau_{f}=15 \mathrm{~ms}\right)$ and slow $\left(\tau_{\mathrm{s}}=500 \mathrm{~ms}\right) \mathrm{Na}^{+}$channel inactivation in an attempt to connect the apparent $\mathrm{Na}^{+}$channel inactivation (Fig. 7A) with the increase in spike threshold over multiple spikes (Fig. $8 C, D) . \boldsymbol{i}$, When driven by a step current, the model produces a small number of spikes at frequencies consistent with the data; however, the neuron quickly ceases discharge despite continuous application of the strong positive current. ii, This result can be easily understood in terms of the dynamic spike threshold $(\theta)$, which increases because of cumulative slow inactivation of the $\mathrm{Na}^{+}$ channel ( $h_{f}$ and $h_{s}$ not shown). Note that the threshold changes by $\sim 4 \mathrm{mV}$ (gray shading) over the course of a few spikes, in line with the upper bound for threshold increases seen between DL cell spikes (Fig. 8C). Our model parameter set gave an initial threshold of $-44.6 \mathrm{mV}$ in close agreement with the Aptoronotus data ( $-45 \mathrm{mV}$, Fig. $4 E)$.

hippocampal neurons by at least $8 \mathrm{mV}$ under basal conditions (Lüscher and Slesinger, 2010) and have been shown to set the RMP of dorsal cochlear nucleus (DCN) neurons to a hyperpolarized level (Ceballos et al., 2016). DL neurons also have a high spike threshold and theoretical analyses suggest this may attributed to a low density of voltage-gated $\mathrm{Na}^{+}$channels (Platkiewicz and Brette, 2010). Furthermore, our results also imply the presence of HVA $\mathrm{Ca}^{2+}$ channels, which activate a strong SK channelmediated AHP that strongly reduces current-evoked spiking. We propose that the combination of a hyperpolarized RMP, the low input resistance at hyperpolarized potentials (Table 1), a high spike threshold and strong AHPs will greatly reduce $\mathrm{DL}$ cell excitability and therefore prevent incoming excitatory synaptic input from driving strong spiking responses.
An unusual and, we believe, critical feature of DL neurons is that they exhibit long-lasting spike threshold adaptation (i.e., threshold fatigue); our modeling suggests that this is due to $\mathrm{Na}^{+}$channels exhibiting slow recovery from inactivation. In mammalian cortical neurons, the $\mathrm{Na}^{+}$ channel's slow recovery from inactivation can last up to a few seconds and can regulate the neuron's excitability; in particular, the slow inactivation of dendritic $\mathrm{Na}^{+}$channels in CA1 neurons can attenuate back-propagating action potentials (Jung et al., 1997). In addition, the link between a sustained spike threshold increase and the slow inactivation of $\mathrm{Na}^{+}$channels has previously been suggested for hippocampal CA1 pyramidal neurons (Henze and Buzsáki, 2001). This spike threshold adaptation mechanism was later used to model time cells using a recurrent network model (Itskov et al., 2011; see below). We note 
Table 2. Difference in spike threshold and resting membrane across multiple cell types

\begin{tabular}{|c|c|c|c|c|c|c|}
\hline \multirow[b]{2}{*}{ Values in mV } & \multicolumn{2}{|c|}{ "Hippocampus" } & \multicolumn{2}{|c|}{ L4 sensory cortex } & \multicolumn{2}{|c|}{ Primary sens. cells } \\
\hline & DL cells & $\begin{array}{c}\text { DG granule } \\
\text { cells }^{a}\end{array}$ & $\begin{array}{l}\text { Barrel } \\
\text { field }^{\mathrm{b}}\end{array}$ & $\begin{array}{l}\text { Visual } \\
\text { cortex }^{\mathrm{C}}\end{array}$ & $\begin{array}{l}\text { ELL Pyr } \\
\text { ON cells }\end{array}$ & $\begin{array}{l}\text { DCN Pyr } \\
\text { Cells }^{f}\end{array}$ \\
\hline Spike threshold & -45.3 & -40.8 & -45.1 & $\sim-63.5$ & $-62.9^{d}$ & -48.1 \\
\hline RMP & -76.7 & -74.7 & -63.0 & -72.0 & $-67.8^{\mathrm{e}}$ & -62.7 \\
\hline Threshold-RMP & 31.4 & 33.9 & 17.9 & 8.5 & 4.9 & 14.6 \\
\hline
\end{tabular}

${ }^{a}$ Kowalski et al. (2016), in vivo, threshold: used point of first derivative which exceeded $20 \mathrm{~V} \mathrm{~s}^{-1}$.

b Yu et al. (2016), in vivo, threshold: used point of first derivative which exceeded three times the average first derivative.

'Wilent and Contreras (2005), in vivo, threshold: used peak of second derivative, values were averaged from the data for preferred direction and non-preferred direction.

dMehaffey et al. (2008), in vitro, threshold: used point of first derivative which was eight times greater than SD.

e Berman and Maler (1998), in vitro.

${ }^{\mathbf{f}} \mathrm{Li}$ et al. (2013), in vitro, threshold: used point of first derivative which exceeded $10 \mathrm{~V} \mathrm{~s}^{-1}$.

that the AHP and slowly recovering $\mathrm{Na}^{+}$inactivation have very different effects on neuron excitability (Benda et al., 2010). The dynamical interaction of these biophysical mechanisms (not currently known) will likely be a critical determinant of the spiking response of DL neurons to their time varying synaptic input. Developing a high quality model of DL cells will be an essential next step in connecting the dynamics of the DL recurrent network (Trinh et al., 2016 ) to in vivo imaging/recording and behavioral studies on spatial learning in the dark (Jun et al., 2016).

\section{The biophysical properties of DL neurons suggest that they are sparse coders}

The main properties that contribute to low DL neuron firing rates are the very depolarized spike threshold and hyperpolarized RMP (Table 2); these parameters are highly variable but typically lead to a large $(\sim 32 \mathrm{mV})$ barrier that excitatory input must exceed to evoke spiking (Table 2). This contrasts sharply with the first order electrosensory pyramidal cells within the ELL. Their barrier from rest to spiking is a mere $4.9 \mathrm{mV}$ (Table 2) and they can even respond to weak signals with discharge frequencies over $100 \mathrm{~Hz}$. ELL pyramidal neurons also recover rapidly from spike induced increases in spike threshold, i.e., threshold fatigue (tens of milliseconds; Chacron et al., 2007). It is hypothesized that these properties are responsible for the ability of pyramidal cells to densely encode spatial and social electrosensory signals (Vonderschen and Chacron, 2011). The low barrier from RMP to spike threshold is also seen in primary auditory

Table 3. Statistical table

\begin{tabular}{|c|c|c|c|c|}
\hline & Data structure & & Type of statistical test & Power \\
\hline a & $\begin{array}{l}\text { Difference between the average variances } \\
\text { of the RMP }\end{array}$ & Control vs kynurenic acid & Paired $t$ test & $p=0.0383$ \\
\hline b & Difference between the average RMP & Control vs kynurenic acid & Paired $t$ test & n.s. $(p=0.7372)$ \\
\hline d & resistance (hyperpolarizing vs depolarizing) & $T \mathrm{TX}$ & Paired $t$ test & $p=9.9 \times 10^{-6}$ \\
\hline e & & QX-314 & Paired $t$ test & $p=2.3 \times 10^{-4}$ \\
\hline$f$ & Difference between the input & Control vs TTX & One-way ANOVA & n.s. $(p=0.32)$ \\
\hline i & for depolarizing current injections & Control vs QX-314 & One-way ANOVA & n.s. $(p=0.07)$ \\
\hline j & Difference in AHP amplitude & Control vs UCL1684 & Two-sample $t$ test & $p=0.0003$ \\
\hline $\mathrm{k}$ & & Control vs EBIO & Two-sample $t$ test & $p=0.001$ \\
\hline | & Difference in AHP area under the curve & Control vs UCL1684 & Two-sample $t$ test & $p=0.0002$ \\
\hline $\mathrm{m}$ & & Control vs EBIO & Two-sample $t$ test & $p=0.00002$ \\
\hline $\mathrm{n}$ & Difference in DL neuron current-evoked & Control vs UCL1684 & Two-way ANOVA & $p=0.0013$ \\
\hline s & spike height & UCL1684 vs BAPTA & Two-way ANOVA & $1.6 \times 10^{-6}$ \\
\hline $\mathrm{t}$ & & Control vs UCL1684 & Two-way ANOVA & n.s. $(p=0.14)$ \\
\hline$u$ & Difference in DL neuron current-evoked & Control vs BAPTA & Two-way ANOVA & $p=1.3 \times 10^{-31}$ \\
\hline $\mathrm{v}$ & spike width & UCL1684 vs BAPTA & Two-way ANOVA & $p=3.7 \times 10^{-10}$ \\
\hline w & & $\begin{array}{l}\text { Control vs UCL1684 } \\
\text { (first } 3 \text { spikes only) }\end{array}$ & Two-way ANOVA & n.s. $(p=0.24)$ \\
\hline$x$ & AHP reduction between first and & Non-burst spike pairs & One sample $t$ test & $p=4.45 \times 10^{-27}$ \\
\hline y & second spike & Initial burst spike pairs & One sample $t$ test & $p=1.26 \times 10^{-13}$ \\
\hline z & Spike threshold increase between first & Non-burst spike pair & One sample $t$ test & $p=1.24 \times 10^{-22}$ \\
\hline aa & and second spike & Initial burst spike pairs & One sample $t$ test & $p=8.30 \times 10^{-28}$ \\
\hline
\end{tabular}

n.s. $=$ not significant. 
neurons and in layer 4 cells of the primary visual and somatosensory cortex (Table 2). Although no precise estimates are available, it appears likely that all these lowlevel sensory neurons encode sensory input much more densely than neurons in the hippocampus.

Hippocampal neurons such as DG granule cells are nearly silent at rest, and discharge very sparsely in response to the animal's spatial location, i.e., place field (Diamantaki et al., 2016). The low excitability in mature granule cells was shown to be partly due to the constitutive activity of GIRK channels (Gonzalez et al., 2018). We hypothesize that a similar mechanism is contributing to the low RMP of DL neurons in fish, which may partly explain why the difference between RMP and spike threshold is nearly identical in DL and DG cells (Table 2).

With the above examples in mind, we hypothesize that the key biophysical signatures of sparse coding is, for all neurons, a large gap between the RMP and the spike threshold. We further hypothesize that DL neurons will sparsely encode the spatial relations required for memory guided navigation.

\section{Can the DL network transform PG sequential encounter time stamps to a spatial map?}

Previous studies have investigated electrosensory spatial learning in a related gymnotiform fish (Jun et al., 2016; Fotowat et al., 2019). Jun et al., showed that these fish can locate food relative to landmarks in the dark because, after learning, they rapidly navigated to the remembered food location during probe trials (no food). Fotowat et al. (2019) showed that neurons within DD, which has strong reciprocal connections with DL (Giassi et al., 2012a; Elliott et al., 2017), discharged when the fish was engaged in active sensing movements near landmarks. Together, these studies imply that $\mathrm{DL}$ is engaged in learning and storing the spatial memories of the relative location of landmarks and food. The electrosense is very local and, for most of their trajectory, the fish had no external sensory cues (Jun et al., 2016). This led Jun et al. to argue that, after leaving a landmark, the fish used the path integration of speed and orientation signals to continuously update its current location and thus compute the trajectory to the remembered food location. Path integration information was assumed to potentially derive from lateral line receptors, vestibular afferents, proprioceptors and vestibular afferents. Bastian (1995) has previously reported that there are brainstem proprioceptive neurons in the gymnotiform fish that are capable of signaling tail bending. Recently, Wallach et al. (2018) found PG neurons are responsive to continuous lateral line input, confirming a second potential source of information related to the fish's speed. A recent study in the larval zebrafish has demonstrated that vestibular input can evoked strong and widespread activity in the telencephalon that, from the images presented, likely includes DL (Favre-Bulle et al., 2018). We now hypothesize that an encounter with a landmark triggers an autonomous "moving bump" in the DL recurrent network and this is the primary driver for the fish's estimation of its changing location during its landmark-to-food trajectories. While proprioceptive, lat- eral line and vestibular input are important, we now hypothesize they merely modulate the essential intrinsic DL network dynamics. We elaborate on this hypothesis below.

In gymnotiform fish, PG cells respond to object motion (electrosensory and visual; Wallach et al., 2018). Anatomic studies indicate that these responses are driven by tectal input (Giassi et al., 2011). The gymnotiform tectum maintains a topographic representation of electrosensory input and tracks continuous object motion (Bastian, 1982). PG neurons generate a major transformation of their tectal input, the majority of PG motion sensitive cells lose topographic information and respond over the fish's entire body but only to object motion start (all cells) and stop (some cells) and not the intervening continuous motion (Wallach et al., 2018). Wallach et al. proposed that, during navigation in the dark, these PG cells will respond transiently when any part of the fish's body first encounters a landmark (or food), i.e., the response of the cell when the experimenter moves an object toward the fish is equivalent to its response when the fish moves near a landmark or food. Wallach et al. further proposed that the time interval between encounters could be "read out" from the change in second versus first encounter firing rates of a subset of DL cells.

In the following discussion, we borrow extensively from work on "time" and "place" cells in the mammalian hippocampus using, in particular, the very thorough papers of Kraus et al. (2013) and Pastalkova et al. (2008) as well as the related theoretical papers of Itskov et al. (2011) and Rajan et al. (2016). Kraus et al. (2013) describe hippocampal neurons that respond at specific times during a rat's motion on a treadmill. These experiments carefully dissociated time from place so that the authors were able to demonstrate the existence of time cells, traditional place cells as well as cells with information on both the time and distance traveled. Pastalkova et al. (2008) and Itskov et al. (2011) had previously argued that sequential activation of cell assemblies is internally generated by hippocampal dynamics and can give rise to time cells independent of sensory input. Kraus et al. (2013) extended this hypothesis and argued that their time cells were driven by both internal network dynamics and external cues such as treadmill speed.

The theoretical papers of Itskov et al. (2011) and Rajan et al. (2016) asked: how might the intrinsic activity of a neural network result in the sequential activation of neuron assemblies, e.g., time cells? Both papers started with the same core architecture, a local excitatory recurrent network that, once activated, was capable of sustained discharge. This is the "bump attractor" hypothesis originally formulated to explain the sustained activity of neurons during a working memory task (Wang, 1999; Wimmer et al., 2014). The theoretical analysis of Wang (1999) demonstrated that slow excitatory synapses, i.e., mediated by NMDA receptors, were required for bump dynamics. Both Itskov et al. (2011) and Rajan et al. (2016) generated "cell assembly sequences" by destabilizing the bump attractor dynamics. Itskov et al. (2011) accomplished this by introducing spike threshold adaptation 
with a long recovery time constant. In contrast, Rajan et al. (2016) destabilized the bump by introducing asymmetries in synaptic strengths within the attractor so that the attractor dynamics would generate a sequential activation of the cell assembly; a process which necessitated both recurrent connections and external input. In both cases, sequential activation of neurons within the cell assembly are able to produce time cells or other sequential outputs. A recent paper (Heys and Dombeck, 2018) has also suggested that time cells of the entorhinal cortex might be generated by moving bumps in entorhinal recurrent attractor network (Zutshi et al., 2018). This paper did not, however, explicitly discuss the mechanism by which the putative "bumps" would move.

Our earlier work (Trinh et al., 2016) demonstrated that DL contains excitatory local recurrent networks; our earlier work had already demonstrated that DL is highly enriched in NMDA receptors (Harvey-Girard et al., 2007). Trinh et al. (2016), therefore, hypothesized that the DL recurrent network supported bump attractor dynamics capable of memory storage. Our noisy cells suggest that the recurrent connections within $\mathrm{DL}$ are, in fact, capable of supporting autonomous discharge. We have now demonstrated that DL neurons exhibit the same threshold adaptation used in the Itskov et al. (2011) model, thus suggesting that the putative DL bumps may not be stable attractors. We have not yet studied the properties of either PG-derived or intrinsic synapses in DL and therefore cannot evaluate whether Rajan et al. (2016)'s architecture might apply. In accordance with the Itskov model, we hypothesize that $\mathrm{DL}$ contains unstable bump attractor neural networks that are capable of supporting autonomous sequential activation and thus DL time cells. We assume that, when the fish initially encounters a landmark, the resulting electrosensory-evoked transient discharge in a subset of PG neurons triggers activity in a small region of DL (Giassi et al., 2012b). This activity will then propagate through a subset of the DL network forming a cell assembly temporal sequence (time cells). Following Kraus et al. (2013), we further hypothesize that the sequential activity in this network is modified by ongoing self-motion sensory input, the vestibular, lateral line and proprioceptive input mentioned above. These inputs provide the path integration signals that converts the time cell sequence to a location cell sequence. In functional terms, we propose that the propagation of neural activity in the DL network represents the fish's estimate of where it is located along the trajectory between a landmark and food. When the fish reaches the food (or another landmark), PG neurons would again discharge to signal the total time/distance traveled (Wallach et al., 2018) and the potential start of a new trajectory. In this model, learning a trajectory from a particular landmark to food would consist of strengthening the synaptic connections of the moving bump induced by that landmark so as to represent the time/location sequence leading from the landmark to food. Such strengthening might result in a Rajan et al. (2016) type mechanism in which directed bump movement was now also a consequence of asymmetric synaptic strengthening.
Our hypotheses are at the moment not testable, because testing would require population recording from or visualizing activity across a large portion of the DL network. What is needed is a teleost that is transparent when adult, whose neurons express a genetically encoded calcium indicator (e.g., gCamp6) and whose pallium might be activated by ethologically relevant transient signals. Fortunately, such a model system has recently become available (Schulze et al., 2018) and may permit direct tests of our hypotheses.

\section{References}

Alreja M, Aghajanian GK (1994) QX-314 blocks the potassium but not the sodium-dependent component of the opiate response in locus coeruleus neurons. Brain Res 639:320-324.

Azouz R, Gray CM (2000) Dynamic spike threshold reveals a mechanism for synaptic coincidence detection in cortical neurons in vivo. Proc Natl Acad Sci USA 97:8110-8115.

Barry C, Burgess N (2014) Neural mechanisms of self-location. Curr Biol 24:R330-R339.

Bastian J (1982) Vision and electroreception: integration of sensory information in the optic tectum of the weakly electric fish Apteronotus albifrons. J Comp Physiol A 147:287-297.

Bastian J (1995) Pyramidal-cell plasticity in weakly electric fish: a mechanism for attenuating responses to reafferent electrosensory inputs. J Comp Physiol A 176:63-73.

Benda J, Maler L, Longtin A (2010) Linear versus nonlinear signal transmission in neuron models with adaptation currents or dynamic thresholds. J Neurophysiol 104:2806-2820.

Berman N, Maler L (1998) Inhibition evoked from primary afferents in the electrosensory lateral line lobe of the weakly electric fish (Apteronotus leptorhynchus). Journal of 768 Neurophysiology 80 : 3173-3196.

Berman NJ, Plant J, Turner R, Maler L (1997) Excitatory amino acid receptors at a feedback pathway in the electrosensory system. $J$ Neurophysiol 78:1869-1881.

Berman N, Maler L (1998) Inhibition evoked from primary afferents in the electrosensory lateral line lobe of the weakly electric fish (Apteronotus leptorhynchus). J Neurophysiol 80:3173-3196.

Berman N, Dunn RJ, Maler L (2001) Function of NMDA receptors and persistent sodium channels in a feedback pathway of the electrosensory system. J Neurophysiol 86:1612-1621.

Carr CE, Maler L, Sas E (1982) Peripheral organization and central projections of the electrosensory organs in gymnotiform fish. $J$ Comp Neurol 211:139-153.

Ceballos CC, Li S, Roque AC, Tzounopoulos T, Leao RM (2016) $I_{\mathrm{h}}$ equalizes membrane input resistance in a heterogeneous population of fusiform neurons in the dorsal cochlear nucleus. Front Cell Neurosci 10:249.

Chacron MJ, Lindner B, Longtin A (2007) Threshold fatigue and information transfer. J Comput Neurosci 23:301-311.

Dangelmayer S, Benda J, Grewe J (2016) Weakly electric fish learn both visual and electrosensory cues in a multisensory object discrimination task. J Physiol Paris 110:182-189.

Deuker L, Bellmund JL, Navarro Schröder T, Doeller CF (2016) An event map of memory space in the hippocampus. Elife 5:e16534.

Diamantaki M, Frey M, Berens $P$, Preston-Ferrer P, Burgalossi A (2016) Sparse activity of identified dentate granule cells during spatial exploration. Elife 5:e20252.

Eichenbaum $\mathrm{H}$ (2014) Time cells in the hippocampus: a new dimension for mapping memories. Nat Rev Neurosci 15:732-744.

Eichenbaum $\mathrm{H}$ (2017) On the integration of space, time, and memory. Neuron 95:1007-1018.

Ellerkmann RK, Riazanski V, Elger CE, Urban BW, Beck H (2001) Slow recovery from inactivation regulates the availability of voltage-dependent $\mathrm{Na}(+)$ channels in hippocampal granule cells, hilar neurons and basket cells. J Physiol 532:385-397. 
Elliott SB, Harvey-Girard E, Giassi AC, Maler L (2017) Hippocampallike circuitry in the pallium of an electric fish: possible substrates for recursive pattern separation and completion. J Comp Neurol 525:8-46.

Ellis LD, Mehaffey WH, Harvey-Girard E, Turner RW, Maler L, Dunn RJ (2007) SK channels provide a novel mechanism for the control of frequency tuning in electrosensory neurons. J Neurosci 27: 9491-9502.

Ellis LD, Maler L, Dunn RJ (2008) Differential distribution of SK channel subtypes in the brain of the weakly electric fish Apteronotus leptorhynchus. J Comp Neurol 507:1964-1978.

Favre-Bulle IA, Vanwalleghem G, Taylor MA, Rubinsztein-Dunlop H, Scott EK (2018) Cellular-resolution imaging of vestibular processing across the larval zebrafish brain. Curr Biol 28:3711-3722.e3.

Fleidervish IA, Friedman A, Gutnick MJ (1996) Slow inactivation of $\mathrm{Na}+$ current and slow cumulative spike adaptation in mouse and guinea-pig neocortical neurones in slices. J Physiol 493:83-97.

Fotowat H, Lee C, Jun JJ, Maler L (2019) Neural activity in a hippocampus-like region of the teleost pallium is associated with active sensing and navigation. Elife 8:e44119.

Ganz J, Kroehne V, Freudenreich D, Machate A, Geffarth M, Braasch I, Kaslin J, Brand M (2014) Subdivisions of the adult zebrafish pallium based on molecular marker analysis. F1000Research 3:308.

Gentet LJ, Stuart GJ, Clements JD (2000) Direct measurement of specific membrane capacitance in neurons. Biophys J 79:314320.

Giassi AC, Maler L, Moreira JE, Hoffmann A (2011) Glomerular nucleus of the weakly electric fish, Gymnotus sp.: cytoarchitecture, histochemistry, and fiber connections-insights from neuroanatomy to evolution and behavior. J Comp Neurol 519:16581676.

Giassi AC, Ellis W, Maler L (2012a) The organization of the gymnotiform fish pallium in relation to learning and memory: III. Intrinsic connections. J Comp Neurol 520:3369-3394.

Giassi AC, Duarte TT, Ellis W, Maler L (2012b) The organization of the gymnotiform fish pallium in relation to learning and memory: II. Extrinsic connections. J Comp Neurol 520:3338-3368.

Giassi AC, Harvey-Girard E, Valsamis B, Maler L (2012c) The organization of the gymnotiform fish pallium in relation to learning and memory: I. Cytoarchitectonics and cellular morphology. J Comp Neurol 520:3314-3337.

Gonzalez JC, Epps SA, Markwardt SJ, Wadiche JI, OverstreetWadiche L (2018) Constitutive and synaptic activation of GIRK channels differentiates mature and newborn dentate granule cells. J Neurosci 38:6513-6526.

Graff C, Kaminski G, Gresty M, Ohlmann T (2004) Fish perform spatial pattern recognition and abstraction by exclusive use of active electrolocation. Curr Biol 14:818-823.

Hartley T, Lever C, Burgess N, O'Keefe J (2014) Space in the brain: how the hippocampal formation supports spatial cognition. Philos Trans R Soc Lond B Biol Sci 369:20120510.

Harvey-Girard E, Maler L (2013) Dendritic SK channels convert NMDA-R-dependent LTD to burst timing-dependent plasticity. J Neurophysiol 110:2689-2703.

Harvey-Girard E, Dunn RJ, Maler L (2007) Regulated expression of $\mathrm{N}$-methyl-D-aspartate receptors and associated proteins in teleost electrosensory system and telencephalon. J Comp Neurol 505: 644-668.

Harvey-Girard E, Tweedle J, Ironstone J, Cuddy M, Ellis W, Maler L (2010) Long-term recognition memory of individual conspecifics is associated with telencephalic expression of Egr-1 in the electric fish Apteronotus leptorhynchus. J Comp Neurol 518:2666-2692.

Harvey-Girard E, Giassi AC, Ellis W, Maler L (2012) The organization of the gymnotiform fish pallium in relation to learning and memory: IV. Expression of conserved transcription factors and implications for the evolution of dorsal telencephalon. J Comp Neurol 520: 3395-3413.
Henze DA, Buzsáki G (2001) Action potential threshold of hippocampal pyramidal cells in vivo is increased by recent spiking activity. Neuroscience 105:121-130.

Heys JG, Dombeck DA (2018) Evidence for a subcircuit in medial entorhinal cortex representing elapsed time during immobility. Nat Neurosci 21:1574-1582.

Itskov V, Curto C, Pastalkova E, Buzsáki G (2011) Cell assembly sequences arising from spike threshold adaptation keep track of time in the hippocampus. J Neurosci 31:2828-2834.

Jun JJ, Longtin A, Maler L (2016) Active sensing associated with spatial learning reveals memory-based attention in an electric fish. J Neurophysiol 115:2577-2592.

Jung HY, Mickus T, Spruston N (1997) Prolonged sodium channel inactivation contributes to dendritic action potential attenuation in hippocampal pyramidal neurons. J Neurosci 17:6639-6646.

Kowalski J, Gan J, Jonas P, Pernia-Andrade AJ (2016) Intrinsic membrane properties determine hippocampal differential firing pattern in vivo in anesthetized rats. Hippocampus 26:668-682.

Krahe R, Maler L (2014) Neural maps in the electrosensory system of weakly electric fish. Curr Opin Neurobiol 24:13-21.

Kraus BJ, Robinson RJ 2nd, White JA, Eichenbaum H, Hasselmo ME (2013) Hippocampal "time cells": time versus path integration. Neuron 78:1090-1101.

Li S, Choi V, Tzounopoulos T (2013) Pathogenic plasticity of Kv7.2/3 channel activity is essential for the induction of tinnitus. Proc Natl Acad Sci U S A 110:9980-9985.

Luján R, Aguado C (2015) Localization and targeting of GIRK channels in mammalian central neurons. Int Rev Neurobiol 123:161200.

Lüscher C, Slesinger PA (2010) Emerging roles for G protein-gated inwardly rectifying potassium (GIRK) channels in health and disease. Nat Rev Neurosci 11:301-315.

MacDonald CJ, Lepage KQ, Eden UT, Eichenbaum H (2011) Hippocampal "time cells" bridge the gap in memory for discontiguous events. Neuron 71:737-749.

Maler $L$ (1979) The posterior lateral line lobe of certain gymnotoid fish. Quantitative light microscopy. J Comp Neurol 183:323-363.

Maler L, Sas EK, Rogers J (1981) The cytology of the posterior lateral line lobe of high frequency weakly electric fish (Gymnotidae): dendritic differentiation and synaptic specificity in a simple cortex. J Comp Neurol 195:87-139.

Marcoux CM, Clarke SE, Nesse WH, Longtin A, Maler L (2016) Balanced ionotropic receptor dynamics support signal estimation via voltage-dependent membrane noise. J Neurophysiol 115:530545.

Martinez D, Metzen MG, Chacron MJ (2016) Electrosensory processing in Apteronotus albifrons: implications for general and specific neural coding strategies across wave-type weakly electric fish species. J Neurophysiol 116:2909-2921.

Mathieson WB, Maler L (1988) Morphological and electrophysiological properties of a novel in vitro preparation: the electrosensory lateral line lobe brain slice. J Comp Physiol A 163:489-506.

Mehaffey WH, Maler L, Turner RW (2008) Intrinsic Frequency Tuning in ELL Pyramidal Cells Varies Across Electrosensory Maps. J Neurophysiol 99:2641-2655.

Mickus T, Jung H, Spruston N (1999) Properties of slow, cumulative sodium channel inactivation in rat hippocampal CA1 pyramidal neurons. Biophys J 76:846-860.

Modi MN, Dhawale AK, Bhalla US (2014) CA1 cell activity sequences emerge after reorganization of network correlation structure during associative learning. Elife 3:e01982.

Mueller T, Wullimann MF (2009) An evolutionary interpretation of teleostean forebrain anatomy. Brain Behav Evol 74:30-42.

Newport C, Wallis G, Reshitnyk Y, Siebeck UE (2016) Discrimination of human faces by archerfish (Toxotes chatareus). Sci Rep 6:27523.

Northcutt RG (2006) Connections of the lateral and medial divisions of the goldfish telencephalic pallium. J Comp Neurol 494:903-943. 
Northcutt RG (2008) Forebrain evolution in bony fishes. Brain Res Bull 75:191-205.

Palmer MJ (2006) Modulation of $\mathrm{Ca}(2+)$-activated $\mathrm{K}+$ currents and $\mathrm{Ca}(2+)$-dependent action potentials by exocytosis in goldfish bipolar cell terminals. J Physiol 572:747-762.

Pastalkova E, Itskov V, Amarasingham A, Buzsáki G (2008) Internally generated cell assembly sequences in the rat hippocampus. Science 321:1322-1327.

Perkins KL, Wong RK (1995) Intracellular QX-314 blocks the hyperpolarization-activated inward current lq in hippocampal CA1 pyramidal cells. J Neurophysiol 73:911-915.

Platkiewicz J, Brette R (2010) A threshold equation for action potential initiation. PLoS Comput Biol 6:e1000850.

Platkiewicz J, Brette R (2011) Impact of fast sodium channel inactivation on spike threshold dynamics and synaptic integration. PLoS Comput Biol 7:e1001129.

Rajan K, Harvey CD, Tank DW (2016) Recurrent network models of sequence generation and memory. Neuron 90:128-142.

Ranganath C, Hsieh LT (2016) The hippocampus: a special place for time. Ann NY Acad Sci 1369:93-110.

Rischawy I, Schuster S (2013) Visual search in hunting archerfish shares all hallmarks of human performance. J Exp Biol 216:30963103.

Rodríguez F, López JC, Vargas JP, Gómez Y, Broglio C, Salas C (2002) Conservation of spatial memory function in the pallial forebrain of reptiles and ray-finned fishes. J Neurosci 22:2894-2903.

Salazar BC, Castillo C, Díaz ME, Recio-Pinto E (1996) Multiple open channel states revealed by lidocaine and QX-314 on rat brain voltage-dependent sodium channels. J Gen Physiol 107:743-754.

Salisbury JP, Sîrbulescu RF, Moran BM, Auclair JR, Zupanc GK, Agar JN (2015) The central nervous system transcriptome of the weakly electric brown ghost knifefish (Apteronotus leptorhynchus): de novo assembly, annotation, and proteomics validation. BMC Genomics 16:166.

Schluessel V, Bleckmann H (2005) Spatial memory and orientation strategies in the elasmobranch Potamotrygon motoro. J Comp Physiol A Neuroethol Sens Neural Behav Physiol 191:695-706.

Schulze L, Henninger J, Kadobianskyi M, Chaigne T, Faustino Al, Hakiy N, Albadri S, Schuelke M, Maler L, Del Bene F, Judkewitz B (2018) Transparent Danionella translucida as a genetically tractable vertebrate brain model. Nat Methods 15:977-983.

Sekerli M, Del Negro CA, Lee RH, Butera RJ (2004) Estimating action potential thresholds from neuronal time-series: new metrics and evaluation of methodologies. IEEE Trans Biomed Eng 51:1665-1672.

Siebeck UE, Litherland L, Wallis GM (2009) Shape learning and discrimination in reef fish. J Exp Biol 212:2113-2119.

Simms BA, Zamponi GW (2014) Neuronal voltage-gated calcium channels: structure, function, and dysfunction. Neuron 82:24-45.

Slesinger PA (2001) lon selectivity filter regulates local anesthetic inhibition of G-protein-gated inwardly rectifying $\mathrm{K}+$ channels. Biophys J 80:707-718.

Talbot MJ, Sayer RJ (1996) Intracellular QX-314 inhibits calcium currents in hippocampal CA1 pyramidal neurons. J Neurophysiol 76:2120-2124.

Trinh AT, Harvey-Girard E, Teixeira F, Maler L (2016) Cryptic laminar and columnar organization in the dorsolateral pallium of a weakly electric fish. J Comp Neurol 524:408-428.

Tsien RW, Lipscombe D, Madison DV, Bley KR, Fox AP (1988) Multiple types of neuronal calcium channels and their selective modulation. Trends Neurosci 11:431-438.

Turner RW, Maler L, Deerinck T, Levinson SR, Ellisman MH (1994) TTX-sensitive dendritic sodium channels underlie oscillatory discharge in a vertebrate sensory neuron. J Neurosci 14:6453-6471.

Vinepinsky E, Perchik S, Ben-Shahar O, Donchin O, Segev R (2018) Representation of border, velocity and speed in the goldfish brain. bioRxiv 291013.

Vonderschen K, Chacron MJ (2011) Sparse and dense coding of natural stimuli by distinct midbrain neuron subpopulations in weakly electric fish. J Neurophysiol 106:3102-3118.

Wallach A, Harvey-Girard E, Jun JJ, Longtin A, Maler L (2018) A time-stamp mechanism may provide temporal information necessary for egocentric to allocentric spatial transformations. Elife 7:e36769.

Wang XJ (1999) Synaptic basis of cortical persistent activity: the importance of NMDA receptors to working memory. J Neurosci 19:9587-9603.

Wilent WB, Contreras D (2005) Dynamics of excitation and inhibition underlying stimulus selectivity in rat somatosensory cortex. Nat Neurosci 8:1364-1370.

Wimmer K, Nykamp DQ, Constantinidis C, Compte A (2014) Bump attractor dynamics in prefrontal cortex explains behavioral precision in spatial working memory. Nat Neurosci 17:431-439.

Yamamoto N, Ito $\mathrm{H}$ (2008) Visual, lateral line, and auditory ascending pathways to the dorsal telencephalic area through the rostrolateral region of the lateral preglomerular nucleus in cyprinids. J Comp Neurol 508:615-647.

Yamamoto N, Ishikawa Y, Yoshimoto M, Xue HG, Bahaxar N, Sawai $\mathrm{N}$, Yang $\mathrm{CY}$, Ozawa $\mathrm{H}$, Ito $\mathrm{H}$ (2007) A new interpretation on the homology of the teleostean telencephalon based on hodology and a new eversion model. Brain Behav Evol 69:96-104.

Yu J, Gutnisky DA, Hires SA, Svoboda K (2016) Layer 4 fast-spiking interneurons filter thalamocortical signals during active somatosensation. Nat Neurosci 19:1647-1657.

Zhou W, Arrabit C, Choe S, Slesinger PA (2001) Mechanism underlying bupivacaine inhibition of $\mathrm{G}$ protein-gated inwardly rectifying $\mathrm{K}+$ channels. Proc Natl Acad Sci USA 98:6482-6487.

Zutshi I, Fu ML, Lilascharoen V, Leutgeb JK, Lim BK, Leutgeb S (2018) Recurrent circuits within medial entorhinal cortex superficial layers support grid cell firing. Nat Commun 9:3701. 